\title{
FIRST REPORT OF THE NORTH MANCHURIAN PLAGUE PREVENTION SERVICE.
}

By WU LIEN-TEH (G. L. TUCK), M.A., M.D., B.C. (Cantab.), Director and Chief Medical Officer, and late President of the International Plague Conference, 1911.

(With Plates VI-XVI, 1 Map, and 4 Plans)

\section{CONTENTS.}

PAGE

I. Introduction $. \quad+\quad \cdot \quad \cdot \quad \cdot \quad \cdot \quad \cdot \quad \cdot \quad \cdot \quad \cdot \quad 238$

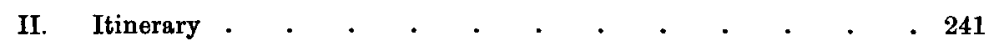

III. Manchouli . . . • . . . . . . . . 242

IV. Professor Zabolotny's work at Harbin . . . . . . . 252

V. Work at Borsja, July 22nd-29th, 1911 . $\quad . \quad$. $\quad . \quad$. $\quad 254$

VI. At Manchouli, July 29th-August 3rd, 1911 - $\quad$ • . . . 256

VII. Work in Mongolia, August 4th-13th, 1911 . $\quad . \quad$. . 257

VIII. The Tarbagan and its parasites. . . . . . . . 260

IX. Susceptibility of the Tarbagan to Anthrax . . . . . . 270

X. Investigation into reported outbreaks of Plague at Puk'uei $\quad . \quad 271$

XI. Evidence associating the Tarbagan with plague and conclusions therefrom . . . . . . . . . . . 272

XII. Recommendations regarding the Tarbagan fur trade. . . . 276

XIII. Outbreak of plague on S.S. Cheongshing . . . . . . . . 277

APPENDIX I. Rectal temperature of the Tarbagan . . . . . . . 278

" II. Details of Tarbagan Burrows . . . . . . . . . . 282

" III. Translation of Chinese Order prohibiting the hunting of

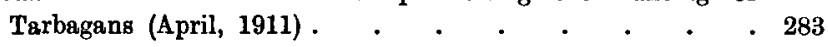

" IV. Temperature observations in Fuchiatien (Harbin) and in Ch'angeh'un . . . . . . . . . . 284

Journ. of Hyg. xinI 16 


\section{INTRODUCTION.}

ImMEDIATELY following on the International Plague Conference held in Mukden in April, 1911, the Chinese Government, anxious to carry out the recommendations of the Conference, instituted the North Manchurian Plague Prevention Service. The chief of these recommendations were briefly :

(a) Systematic investigations should be made as to whether epizootic plague occurs among Tarbagans and other rodents, and, if such exists, an accurate investigation should be made of the nature of the infection.

(b) A general improvement in the sanitary condition of cities and villages, especially with regard to overcrowding, is desirable.

(c) Education of the public by lectures and the issue of pamphlets and handbills, explaining preventive measures in simple language.

(d) The need for isolation of pneumonic-plague patients being urgent, permanent hospitals should be available.

(e) Hospital accommodation for suspected cases of plague should be provided.

(f) Contact quarantine stations should be constructed'

The primary object of the scheme was the formation for North Manchuria of a medical service equipped and ready to act and control any situation that might arise through an outbreak of plague in the district, and also to maintain hospitals at Harbin (the headquarters of the Service), Aigun (Taheiho), Sansing, Lahasusu, Manchouli, and any other town in the district where such an institution might be necessary. In addition medical service was to be given to the poor and destitute, and when the hospital accommodation was not required for plague cases, general medical, surgical and infectious diseases were to be treated in the wards. Further, medical officers in the Service were to instruct the people in general hygiene, etc.

It was hoped that the Service would develop into a Public Health Service for the whole of China. The funds for building the hospitals were to be derived from the current revenue of the three Manchurian Provinces, while the Service was to be maintained out of the Maritime Customs dues.

1 Incidentally, it may be mentioned that the Chinese Government had already established isolation hospitals and segregation camps, each capable of holding from 400 to 2000 persons, at the important railway centres of Shanhaikuan, Mukden and Koupangtzu and at the sea-port of Yingkow (Newchwang). The director of the N. Manchurian Plague Prevention Service is consulting physician to these establishments. 
The Revolution which broke out in October 1911, however, delayed matters; later on the Manchurian Customs, which hitherto had remained a separate entity controlled by the Chinese Government directly, were temporarily given over to swell the general Customs Revenue of China in order to pay the Loans and Boxer Indemnities.

It was not until September 1912 that arrangements were finally made to allot the sum of 60,000 taels $(78,000$ roubles) a year of the Chinese Customs Revenue of Harbin for the maintenance of the Service.

The Manchurian Plague Prevention Service was thus established on a firm basis on October 1st, 1912, although $1 \frac{1}{2}$ years previous to that date, medical officers had been stationed at Manchouli, Harbin, Tsitsihar (capital of Heilungkiang Province), and Lahasusu to carry out the objects for which the Service was founded.

In the preparation of this Report, I have received considerable assistance from my staff, particularly Dr S. P. Chren, M.B., B.C. (Cantab.), Senior Medical Officer at Harbin, and Dr F. E. Reynolds, M.B., Ch.B. (Edin.), Bacteriologist of the Service.

Among the delegates of the International Plague Conference, Mukden, April 1911, it was generally believed that there was a close connection between Plague-or at least the recent epidemic of Pneumonic Plague of Manchuria-and the Tarbagan or Marmot (Arctomys bobac, Schreb.).

So little is known about this animal and the grounds for associating it with Plague were based on such slender scientific evidence-as will appear later in this Report-that it seemed to me the first step in the investigation of this question was to organise an expedition into the country where the Tarbagan abounds, and there to study its habits and the conditions under which it lives and to carry out scientific investigations as to the presence of Plague among the animals.

For the sake of clearness, it is well to state here that the Tarbagan hunting is divided into two seasons :

I. Spring season, lasting from the end of April to the beginning of June.

II. Autumn season, lasting from the middle of August to the end of September.

The subject, however, will be dealt with in greater detail later in this Report.

On the morning of May 26th, 1911, I arrived at Manchouli to make enquiries as to the conditions under which hunting took place, and to gather information which would prove useful in making arrangements $16-2$ 
for an expedition into the Tarbagan country later in the year. My observations made at that time are embodied in this Report. I left Manchouli on the evening of May 29th and returned to Harbin. About this time of the year large numbers of coolies arrive in Harbin principally from the province of Shantung to find work in the north. Most of them obtain employment along the Sungari and Amur rivers. On May 30th I saw a train reach Harbin station with over 1000 coolies; like others from Shantung, they possessed a fine physique and were in the best of health. Soon afterwards official business took me to Peking.

In the beginning of July rumours were afloat that a large number of Tarbagans were dying in the neighbourhood of Scharasone (Transbaikalia, Siberia). On July 11th I left Tientsin with orders to organise an expedition to investigate the matter, as the Chinese Government were most anxious that all measures should be taken to forestall a possible spread of Plague to man. The Manchurian authorities agreed to build hospitals for Plague at all the important centres and instructed me to staff them with properly qualified medical officers; and from the Viceroy at Mukden downwards, all the officials took great interest in the proposed expedition. I quote the following from the Peking Daily News :

\section{Tarbagan Epidemic in Siberia spreading southwards. (Special Dispatch to the P.D.N.)}

$$
\text { Harbin, July 13th. }
$$

"My correspondent at Station Manchouli wires that the Tarbagan epidemic of Siberia is spreading southwards towards the Chinese frontier. Dead marmots are now found as far south as Scharasone which is only thirty-five miles north of the Russian-Chinese frontier. Local measures are sufficiently strict to prevent the disease from entering Manchuria. Some members of the Chinese Scientific Expedition for the study of Tarbagan diseases have already arrived here."

Arriving at Harbin on July 15th, I called on Prolessor Zabolotny, who was at that time working at certain plague problems in the Russian Laboratory of that town. After showing me his specimens and telling me the results of his investigations--a note of which appears in this Report-he invited me and my party to proceed with him to Manchouli in a special car provided by the Chinese Eastern (Russiap) Railway I gladly availed myself of the invitation. It is interesting to note that this was the first scientific expedition sent out by the Chinese Government. 
The Russian party consisted of Professor Zabolotny, Drs Tschourilina (a lady) and Issaief (see Pl. VII, fig. 3). Our own party consisted of Dr Ch'en Sze-pang, M.B. (Cantab.), Dr Tsang Pu and myself. Our investigations form the basis of this Report.

\section{ITINERARY.}

Leaving Harbin we arrived at Manchouli Station on July 21st and arranged that this should be the base of the Chinese Expedition. We gave instructions that huts should be built for us, for the laboratory, and for the animals. The next day $\mathrm{Dr} \mathrm{Ch}^{6} \mathrm{en}$ and myself left for Borsja ${ }^{1}$ (Transbaikal District) to join the Russian party who had their base there. We remained with them for a week, visiting Tschintansk, Arabulak and the neighbouring villages. On July 29th we returned to Manchouli to rejoin our party. A few days afterwards the Russian staff broke up, Prof. Zabolotny and Dr Tschourilina returning to St Petersburg and Dr Issaief to his station on the Russo-Chinese frontier. Our start for Mongolia to make further investigations was delayed by the rainy weather until August 6th. Proceeding westward we reached Charbada on the 7 th, where we encamped for two days. On August 9th we left for Kerloni. As there was no direct way there we had to return to Manchouli and from thence proceeded in a southwesterly direction parallel to the large but shallow river called Kerulen, which after it has passed through Kulun Nor (Kulun See) is called River Argun, and later on becomes the Amur. We travelled southwards, passed Zagan on the east, and after two days reached the large lake, Kulun See. Finally we encamped at Kerloni-a Mongol colony situated on the river-on August the 11th. We then proposed to visit Abagaitui in Siberia by way of Dalai Nor, but our guide informed us that this was impossible, as it would mean crossing a mountainous district where there was no water. On the following day, therefore, we decided to return to Manchouli, which we reached on August 14th. From this date until August 25th we lived at Manchouli, making excursions into the country around and doing experimental work with Tarbagans.

On August 25th I departed from Manchouli in order to enquire into an outbreak of Plague which was reported from Puk'uei (Tsitsibar, capital of Heilungkiang Province) and from thence went back to Harbin. 1 left Dr Ch'en at Manchouli to finish our work there and

${ }^{1}$ Borsja is 121 versts west of and three hours by express train from Manchouli. 
to make any other investigations that might be required. Dr Ch'en's work at this time is incorporated in this Report. He left Manchouli for Harbin on September 30th, 1911, as the evenings were getting too cold for further stay in camp.

\section{Manchouli ${ }^{1}$.}

The principal marts in the Manchurian Provinces for Tarbagan skins are Manchouli and Hailar. Hailar is 116 miles (174 versts) by rail east of Manchouli station, but as the latter is the only Customs station for the district, skins sold in Hailar have to be sent there for exportation. The chief Russian mart is Borsja (Transbaikalia), some 80 miles (121 versts) west.

Manchouli is situated in Chinese territory at the junction of the Chinese Eastern and the Trans-Siberian Railways, and is about ten miles east of the frontier between the Province of Heilungkiang and Siberia. Here are established the Chinese and Russian Customs for the examination of goods and baggage passing along the railway from one country to the other-Manchouli having been opened as a Customs station in February 1907. Most of the information which follows about the place was obtained when I visited the town at the end of May and again in August.

Manchouli (meaning the hamlet of the Manchus) lies 2600 feet above sea level and is surrounded on all sides by low barren mountains. The water is saltish, hard and scarce. The railway zone covers a large area and consists of four sections :

(1) The Private Settlement containing 5000 Russian and 1500 Chinese inhabitants.

(2) The Chinese Eastern Railway Settlement containing about 700 inhabitants, mostly Russians.

(3) The Transbaikal Settlement containing 800 inhabitants.

(4) The River Settlement on the furtber side of the "river"-a shallow ditch some five feet wide. This Settlement used to be occupied by desperadoes and murderers, mostly Caucasians, who carried on a trade in smuggling. It is now in ruins, having been destroyed five years ago by the Russian police who, after a three days' fight, caught and exiled the survivors to Siberia.

Altogether the population of Manchouli may be estimated as consisting of 8000 Russian civilians, Customs officials, etc., 3000 Russian

1 Manchouli is 875 versts or 583 miles by rail west of Harbin. 
troops, and 2000 Chinese, most of whom are of the coolie class. During the Russo-Japanese War there used to be as many as 40,000 to 50,000 people resident at Manchouli.

\section{Occurrence of Plague at Manchouli and surrounding districts.}

In 1898 Prof. Zabolotny was in Mongolia and found Plague in the region he visited. Between this date and $1905 \mathrm{I}$ could gather no reliable information as to the occurrence of the disease in or around Manchouli. Dr Bissemsky, the Russian physician in charge of the railway at Manchouli, supplied me with the following interesting information regarding outbreaks of Plague which had occurred in his district since he went there in 1905:

1905. Plague occurred in August at Dalai Nor ${ }^{1}$ (14 cases) and in Manchouli (4 cases). Total 18 cases. Bubonic type.

1906. Plague occurred in Abagaitui ${ }^{2}$ (Russian territory) (15 cases) and in Manchouli ( 2 cases). Total 17 cases. Pneumonic type.

1907. One case was imported from Transbaikal territory into Manchouli. Bubonic type.

1908. There were no cases of Plague in Manchouli, but there was reason to believe that the disease was present among the Mongols along the Argun River. There is some doubt as to the type of the disease, but it seems probable that it was pneumonic.

1909. No cases reported.

1910. The last epidemic, with 400 cases at Manchouli. Pneumonic type.

To bring it up to date, the above information may be supplemented as follows :

1911. End of August, 5 cases at Scharasone, 4 deaths. Bubonic type. 1912. Beginning of September, near Chita ${ }^{3}$ (capital of Transbaikalia), 3 cases, all fatal. Evidently pneumonic type (confirmed by P. Haffkine).

In regard to the above outbreaks, it is interesting to note that those of 1905, 1906, 1907, 1911 and 1912 were confined to Russians and Cossacks, no Chinese having died : whilst in 1908 only Mongols died.

1 Dalai Nor is the first railway station, 28 versts east of Manchouli.

2 Abagaitui is 20 miles north of Manchouli.

${ }^{3}$ Chita is 447 versts N.W: of Manchouli. 
In the epidemic of 1910-11 both Russians and Chinese were attacked, but mainly the latter; of 4.00 fatal cases at Manchouli only about 15 were Russians, and these were mostly hospital attendants. For some reason which we cannot explain, during the epidemic of 1910-11, the Russians escaped even when some of them lived with Chinese coolies who took the Plague. In considering the occurrence of Plague at and around Manchouli, it must be borne in mind that the disease is endewic in the Kirghiz Steppes ${ }^{1}$, and from time to time this has travelled eastwards giving rise to sporadic outbreaks in Eastern Siberia.

This subject has been treated carefully in a series of articles written by the British Delegate to the Constantinople Board of Health ${ }^{2}$ and by the Russian, Dr Koltshof ${ }^{3}$, quoted by the British Delegate. So important is the subject in reviewing the occurrence of Plague in Manchuria that I quote these articles at some length. For convenience the subject has been considered more or less in chronological order.

Koltshof gives the following summary of the epidemics in the Bukeëf Horde of the Kirghiz Steppes of the Astrakhan government during the twelve years preceding 1911. The disease generally gives rise to two annual epidemics-one in summer, the other in winter.

1898. Up to this year there are said to be no records of Plague in the Bukeëf Horde.

1899. Summer, no outbreak. Winter, 1899-1900, epideınic began on November 15th.

1900. Summer, no outbreak. Winter, 1900-1901, epidemic began on December 23rd.

1901. Summer, no outbreak.

1902. Summer, epidemic began on June 3rd.

1903. No Plague in the Horde, though epidemic elsewhere in the Astrakhan government.

1904. In December, imported from Kirghiz and Cossacks in the Uralsk Province, where 415 persons had died.

1905. Summer, some minor outbreaks. Winter, an exceptionally severe epidemic. From October 13th to February, 1906, some thousand persons lost their lives.

1 The Kirghiz Settlements are situated in the governments of Astrakhan (Europe), Uralsk and Semiretchinsk (Asia). The area covered by these three governments is a very large one.

2 Lancet, April 24th, 1909, Jan. 7th, 1911, June 3rd, 1911, March 9th, 1912.

3 Vratch, No. 35, August 27th, 1911, quoted in Lancet, March 9th, 1912. 
1906. Summer, epidemic began on April 15th. Winter, epidemic 1906-7 ended on February 28th.

1907. Summer, epidemic began on July 26th. Winter, epidemic began on October 11th.

1908. Summer, epidemic began on July 7 th and ended August 3rd. Winter, no outbreak.

1909. Summer, no outbreak. Winter, 1909-10, epidemic began end of October and subsided in February.

1910. Summer, epidemic began on June 15th.

In Odessa, from May 22nd to August 28th, 1910, there were 97 cases of Plague of which 24 were fatal; and at the beginning of October, 1910, there were four cases.

In July, 1910, Plague appeared in the Kirghiz Steppes, namely in the Asiatic province of Semiretchinsk and in two villages of the Abbastin quarter in the Prjevalsk district of that province, there were 17 cases of pneumonic plague, all fatal, between July and August 11th. No further information regarding this outbreak has been published.

In the Uralsk government, in the five villages of the Jambeitinek district, between August 10th and 14th, there were seven cases of plague, with three deaths. It should be noted that the dates given above are according to the Old Style calendar, which is 13 days later than the Gregorian.

Concerning the outbreak of pneumonic plague at Manchouli in the autumn of 1910, the following occurs in Dr Ch'uan Shao-ching's paper read at the International Plague Conference ${ }^{1}$ :

"Observations reported to me by Chinese residents (at Manchouli) show that two carpenters who lived in the house adjoining Wu Kueiling's inn died with spitting of blood on the 10th day of the 9th Moon (October 23rd). These two carpenters had been in the service of a foreman named Chang Wan-shun at Dawoolya (Daurija), a railway station in Siberia situated some six miles west of the boundary line. Chang Wan-shun told me that six or seven of his carpenters had died with blood spitting in Dawoolya on the 13th day of the 8th Moon (September 26th) and said he believed that plague had appeared in Dawoolya before it was known in Manchouli.

"Later on it was found that nine out of twenty coolies, who lived in a small room in Wu Kuei-ling's inn, were suddenly taken ill with blood

${ }_{1}^{1}$ Report of the International Plague Conference, p. 28. 
spitting: One of them was sent to the Russian Plague Hospital, and it was discovered that he suffered from pneumonic plague. Two died in the house that same night, but the rest ran away to different places in the town, and thus disseminated the disease."

Returning to the articles already referred to in the Lancet:

"On October 14th, 1910, 17 deaths from pneumonic plague occurred in the village of Akurai in the district of Chita. During the week ending October 28th, 1910, there were four deaths at Daurija station, two cases at Tarbagatui mines near Petrovsk, and 34 cases at Manchouli.

"In the early part of 1911, Plague was still prevalent at the Kirghiz Steppes. In and near Sartube (in the first Maritime District), there were 31 cases with 29 deaths between January 4th and 20th. At Djaltir, also in Astrakhan government, seven persons in one hut fell ill with plague (February 3rd to 7 th) and three died.

“During the latter part of 1911, outbreaks of plague of greater or lesser extent occurred in various Kirghiz settlements, the disease being particularly active in the Astrakhan government. In the Semiretchinsk government, which is situated close to the Mongolian frontier and to the north of Kashgar', plague appeared on August 31st (Old Style) in the Kirghiz settlement Akskoe in the volost of Tcherikof. By September 14th there had been four cases, all fatal, of pneumonic plague. From Prjevalsk, on September 14th, were reported eight fatal cases of the same disease at a spot near Maryn in the same volost, and two more deaths occurred there on September 16th. By September 20th the epidemic was declared to be at an end.

"In the Uralsk government, situated much more to the west and adjoining the Astrakhan government, five deaths from pneumonic plague occurred in the Uletinsk volost before August 10th. In the same district, in the Turkoman settlement, near Djambent, eight fatal cases of pueumonic plague were recorded between June 29th and August 8th. In the Tchadyrtinsk volost of the same government, eight cases and three deaths from plague of the 'pneumonic and abdominal forms' occurred before September 10th, followed by one death on the 12th, and one fatal case on the 13th. Another case occurred in another settlement five versts away, and the totals by September 16 th had reached ten cases and six deaths.

"In the Astrakhan government, plague was epidemic in the Urotchishche of Saganai from the end of August to middle of September; a score or more cases occurred here. On September 21st the disease

\footnotetext{
1 Capital of Chinese Turkestan.
} 
became epidemic in several other centres. The following table is a summary of the returns :

\begin{tabular}{|c|c|c|c|c|c|}
\hline & Period & & $\begin{array}{l}\text { No. of in- } \\
\text { fected centres }\end{array}$ & Cases & Deaths \\
\hline September & 21st-Nov. & 7th, 1911 & 16 & 73 & 63 \\
\hline-5 &,,,- & 21st, ," & 28 & 120 & 102 \\
\hline ", &,,,- & $28 \mathrm{th}$, & 33 & 139 & 119 \\
\hline ", & ", -Dec. & 19th, ," & 38 & 187. & 166 \\
\hline ," & , - , & 26th, ,, & 43 & 201 & 180 \\
\hline
\end{tabular}

"The infected centres were situated principally, if not entirely, in the Marynsk, the Kamysk-Samara, and the Primorskaia (or Maritime) divisions of the Astrakhan Steppes. The disease was most active in the Ak-tchagyl settlement (15 versts from the above named Saganai), and in those of Sarhube, Kudauysk, Djapalatka, and Autantchagyl. Elsewhere but few cases or deaths occurred in any single centre. While many of the outbreaks were pneumonic in character, this was not invariably the case ${ }^{1 . "}$

"From Oct. 1911 to Feb. 1912, over 200 cases occurred in the Kirghiz Steppes; among the deaths from plague in the Astrakhan government were those of Dr I. Deminsky, a bacteriologist, and his student assistant. In the port of Kherson on the Black Sea a plaguestricken rat was found in September on a ship which had arrived from the port of Odessa, and this gave rise to a suspicion that the latter port had not yet got rid of the epizootic which was formerly reported among its dock rats." Lancet, Dec. 28th, 1912, p. 1811.

\section{Prohibition of Tarbagan Hunting.}

During February 1911, the (Chinese) Prefect of Manchouli prohibited the hunting of the Tarbagan, the penalty for disobeying this order being two months' imprisonment. In the following April a further order increased the punishment to six months' imprisonment (Appendix III). Up to June 1911 several Russian and some twenty Chinese hunters had been arrested and since then no one had been found hunting. The Chinese suffered imprisonment, and the Russian hunters were handed over to the Russian authorities. The punishment meted out to these Russian hunters is believed to have been confiscation of traps and of half of the skins found, the other half being returned after disinfection to the offenders.

On August 11th, 1911, a General Order, No. 26, was issued by the Russian authorities forbidding trade in Marmots, including hunting of

1 British Delegate to Constantinople Board of Health, Lancet, March 9th, 1912. 
animals, preparation of skins, salting of the flesh and fat under penalty of a fine of 500 roubles or three months' imprisonment. From enquiries made from the Russian police at Manchouli on August 21st it appeared that they had read of the Order but up to the time had not received official notice of it from the Head Office in Harbin. Consequently they were not empowered to put any hindrance on the trade in Marmot skins, although since the beginning of the year they had required, before granting permission to export, a formal guarantee that the raw skins had been sent to the local railway doctor for disinfection. How this disinfection had been carried out, or if it could be carried out at all, without spoiling the skins, was not known.

Up to 1908, comparatively few Chinese hunted the Tarbagan. In the autumn of that year and in the autumn of 1909 several thousand Chinese, attracted by the high price paid for the fur, were in the neighbourhood of Manchouli, and in 1910 the number reached 10,000 hunters.

Owing to the Chinese Order prohibiting the hunting of Tarbagans, there were fewer Chinese in Manchouli during 1911 than formerly, and in consequence the low class so-called lodging-houses, which used to be occupied by the hunters, had been left almost empty. The camping grounds just outside the town where the Mongol hunters used to erect their tents during the hunting season were also deserted.

\section{ThE InNS.}

'The iuns are of two kinds-those entirely underground and those partly overground and partly underground. The overground dwellings are brighter since they are more open, by means of windows made either of glass or paper, to the sunlight, but those partially underground are more popular in cold weather because of their greater warmth ${ }^{1}$. The windows of the latter appear just above the ground and their roofs are made of mud. The accommodation in both types of inns is based upon much the same plan. Two, and sometimes three, tiers of berths for the lodgers are present, there being just room enough between the tiers for a man to sit up. In one house I visited there were 40 berths20 above and 20 below - the measurements of the room being only $25 \mathrm{ft}$. square and $14 \mathrm{ft}$. bigh. Even in May the rooms were ill-ventilated and stuffy. In winter when all the windows are closed and the fires are lit

1 In winter the outside temperature as a rule reaches -30 to $-40^{\circ} \mathrm{C}$., and the ground is frozen to a depth of over 6 to 8 feet. 
the stuffiness must be great. Dr Ch'uan visited some of these inns in the winter. His report showed the conditions to be bad in the extreme: in one hut, $15 \mathrm{ft}$. square and $12 \mathrm{ft}$. high, there were packed in three tiers of berths, one above the other, more than 40 people. The windows were closed and there was a heating stove in the middle of the room. The odour was indescribable, being made up of a mixture of foul breath, the vapours of old dirty fur garments and decomposing pelts which were lying alongside the men (PI. VI, figs. 1, 2). The usual way of heating these inns is by means of a k'ang on either side of the central passage leading from the door. A $k^{k}$ ang is a horizontal brick flue about $5 \mathrm{ft}$. wide and $2 \mathrm{ft}$. high, at one end of which is an opening where is lit a fire of wood or Kaoliang (millet) stalk. At the other end of the $k^{k}$ ang an opening is made through the outside wall of the house, and leads to a chimney for the escape of the smoke. Kaoliang stalk is cheaper than wood and hence is usually used in poor houses; the heat produced is not very great but is sufficient to keep the room at 2 to $5^{\circ} \mathrm{C}$. even when the thermometer outside registers $-20^{\circ} \mathrm{C}$. The windows are few in number, and usually made of a wooden framework pasted with white paper, thus keeping in the heat but allowing little sunlight to penetrate. The men eat, sleep, and very often cook in the same room. They sleep in rows with the head against the wall and the feet towards the central passage. There is no partition between adjoining berths so that they can easily breathe and cough into easch other's faces. Their food consists mainly of millet bread, boiled cabbage, and boiled turnips; they have meat perhaps once a month. For board and lodging the hunter pays at least fifteen roubless a month; in busy times, more. The winter clothes usually consist of a pair of padded cotton trousers, padded socks and thick-soled Chinese shoes, two or three layers of body clothing and a long cotton-padded gown reaching to the ankle. In very severe weather they wear in addition long sheepskin garments and fur caps. During winter the men seldom change their clothes which abound with insects, e.g. lice, Heas, but in summer they lay aside their thick outer garments and wash the inner ones, using them alternately. Unless very poor, the winter trousers are then replaced by thinner ones which cost about a rouble $(2 s .1 d$.) each.

In these inns I have found coolies from Shantung and Chihli, Manchus and Mongols ; in addition, the hunters consist of Buriats and Cossacks. These unhealthy huts are owned by Russians and were built originally for their poor class nationals, but perbaps they were never so overcrowded as when Chinese occupied them. 
From 1908 to 1910 , so many people came to the districts to hunt the Tarbagans that the owners of the inns did a roaring business and packed the men in every available space, extra tiers being added whenever possible above those already existing.

It should be remarked that the number of Mongols regularly resident at Manchouli seldom reached a dozen; but at certain times of the year, especially in summer, large caravans consisting of whole Mongol families pitched their tents on the vacant space in front of the Yâmen ${ }^{1}$. At the time of my visit in July 1911, there were nearly fifty families (some 150 people in all) thus encamped. Some lived in tents, others inside their rickety carts. These vehicles have no springs and no metal rims to the wheels. On such occasions the Mongols brought with them for sale horses, cattle and sheep as well as skins. They were very orderly and willingly abided by the rules laid down by the Prefect.

At Manchouli there is a General Hospital under the charge of the Russian doctor Bissemsky. This hospital has accommodation for 40 in-patients as well as separate blocks for infectious diseases and plague. There are besides a post-mortem room and quarters for the attendants.

\section{Proposed Chinese Hospital at Manchouli.}

Soon after the International Plague Conference it was decided to build a plague and a quarantine hospital at Manchouli, and the necessary funds amounting to Taels 40,000 (about $£ 5600$ ) were sanctioned by the Central and Manchurian Governments in May 1911—these funds coming from the surplus of the Plague Prevention Funds which had been voted during the epidemic of 1910-11. The hospital was to have accommodation for 20 plague cases, 20 suspect cases and 150 contact cases, and was to be in charge of a Senior Medical Officer with European degrees resideut permanently with a trained staff. Plans had been submitted and selected and the foundations had been dug out in a vacant piece of ground near to the Yâmen of the Prefect. As Manchouli was so isolated, it was proposed that the bricks should be made locally. By October, 1911, the stones and timber had been carted to the site and a well dug. Winter setting in necessitated the work being stopped temporarily. Soon after came the Revolution in China, followed in January 1912 by the troubles in Mongolia. Among the things destroyed at Manchouli by the Mongols were the schools, the Yâmen, and even the foundations and materials intended for the new hospital.

1 A Yâmen is a Chinese official's residence or place for transacting official business. 


\section{Note on the Fur Trade at Manchouli.}

The Tarbagan hunting is divided into two seasons:

(1) The Spring season lasting from the end of April to the beginning of June.

(2) The Autumn season lasting from the middle of August to the end of September.

The early Spring fur, owing to its being lighter in weight, is more valuable than the heavier fur obtained in the Autumn season. The fur of the Tarbagan is thick, soft and very serviceable in winter; but up to five years ago the export was not great. Then came a big demand from Europe and America, for the fur dealers in London and Leipzig found that if properly cured and dyed, these furs could be turned into imitation sable and seal skins. The following are the Chinese Customs Returns showing the number of skins exported from Manchouli on which duty was charged during the years 1908-1912:

\begin{tabular}{|c|c|c|c|c|c|c|}
\hline Pieces of & 1908 & 1909 & 1910 & 1911 & , 1912 & $\begin{array}{l}\text { Value in Customs } \\
\text { Taels for 1912 } \\
\text { (1 Customs Tael } \\
=\text { Rouble 1 60) }\end{array}$ \\
\hline Fox skins & 407 & 3,502 & 4,378 & 638 & 1,274 & Tls. 5, 096 \\
\hline Gost skins & 3,770 & 2,454 & 4,829 & 1,929 & 1,445 & - \\
\hline Sable skins & 920 & 9,039 & 4,729 & 66 & 62 & $, \quad 1,530$ \\
\hline Sheep skins & 238,479 & 214,104 & 193,147 & 49,689 & 135,278 & - \\
\hline Squirrel skins & 26,234 & 12,983 & 29,043 & 3,080 & 102,312 & - \\
\hline Tarbagan skins & 210,224 & 19,181 & 242,458 & 10,673 . & 55,196 & , 15,769 \\
\hline Total no. of furs & 480,034 & 261,263 & 478,584 & 66,075 & 295,567 & \\
\hline $\begin{array}{l}\text { Percentage of } \\
\text { Tarbagan } \\
\text { akins to total } \\
\text { no. of skins }\end{array}$ & $44 \%$ & $7 \cdot 3 \%$ & $50 \cdot 6 \%$ & $16 \%$ & $18.7 \%$ & 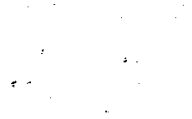 \\
\hline
\end{tabular}

The above figures, however, do not give an adequate idea as to the actual total export of furs from Manchouli, since many skins, as well as hides and bristles, were consigned to Mazijewsskaia, the first station on the railway west of Manchouli and within the 50 verst $^{1}$ duty free zone ${ }^{2}$. Duty was not collected on these furs, the excuse being made that they were for use within the 50 verst free zone. It is estimated that in 1910, two million Tarbagan skins in all were exported from Manchouli. In June 1913 over four million Tarbagan skins were lying at Manchouli ready to be carted by road to Mazijewsskaia for export to Europe. In

13 versts $=2$ miles.

2 By the Treaty of 1881 made between China and Russia, it was agreed that within a zone of 50 versts on either side of the frontier between the two countries, goods shall be admitted free of charge. 
weight it is estimated that 1000 Spring Tarbagan skins weigh 8 Russian poods (288 English pounds); whilst 1000 Autumn skins weigh 14 poods (504 English pounds), counting a pood as 36 pounds. The price rose rapidly from 15 kopecks to 50 kopecks per skin until in 1910, 80 kopecks per skin were realised.

Owing to the increased demand for skins and the consequent rise in .price large numbers of coolies-and especially those from Shantungwere attracted to the spot, and the agricultural peasants left their fields to become 'Tarbagan hunters.' By three months' hunting of the Tarbagans they were able to make as much money as they could have done in the course of a whole year from other occupations.

The Tarbagan skins are mostly sent to Leipzig and London to be cured. At the former town there is a large well-equipped factory for converting the skins into imitation-sable. Of late years, for greater safety, valuable furs have been sent to Europe by parcel post.

\section{Professor Zabolotny's Work at Harbin.}

When I visited Harbin in May and again in July, I called on Professor Zabolotny who was working there at certain problems in connection with plague. I believe that a full account of these has been published already, but it is not available to me. As some of his results and the information he had received influenced to a certain extent our future plans, it seems wise at this point to refer briefly to his results as given to me at that time:

I. He confirmed the fact that the cultures obtained from the donkey at Mukden were Bacillus pestis (see Report of the International Plague Conference, pp. 143-4).

II. His experiments on the infectivity of animals had given interesting results, viz.:

(a) Two donkeys, inoculated subcutaneously with cultures of Bacillus pestis, took plague badly but did not die ${ }^{1}$. These were later on allowed to inhale large numbers of the bacilli through tracheotomy wounds, but both animals resisted the disease. When I saw these animals they were apparently quite healthy and playing about in the field.

(b) Pigs were successfully infected and died.

1 Cf. Strong and Teague. From experiments performed by them, they consider that donkeys are not susceptible to pneumonic plague infection (vide Philippine Journal of Science, Sec. B, Vol. v1. pp. 225-7). 
(c) Dogs took the disease but did not die.

(d) Other animals took plague easily.

(e) Birds were immune.

III. Zabolotny had obtained most interesting results from experiments conducted on 18 monkeys. He tried to protect them with vaccines and serum in large doses, but only two were saved, and these had received extraordinarily large doses. For instance he carried out the following series of experiments:

\begin{tabular}{|c|c|c|c|c|c|c|}
\hline \multirow{2}{*}{\multicolumn{3}{|c|}{ 1st injection (emulsion of dead agar culture) }} & \multirow{2}{*}{$\begin{array}{c}\text { Monkey a } \\
1 \text { c.c. }\end{array}$} & \multirow{2}{*}{$\begin{array}{c}\text { Monkey } b \\
4 \text { c.c. }\end{array}$} & \multirow{2}{*}{$\begin{array}{c}\text { Monkey } c \\
5 \text { c.c. }\end{array}$} & \multirow{2}{*}{$\begin{array}{l}\text { Monkey } d \\
25 \text { c.c. }\end{array}$} \\
\hline & & & & & & \\
\hline 2nd , , & ", & , & 2 & 5 & 10 & 30 \\
\hline 3rd & " $\quad "$ &, & $\mathbf{3}$ & 5 & 10 & - \\
\hline $\begin{array}{r}\text { Result a } \\
\text { trach }\end{array}$ & $\begin{array}{l}\text { aling } B . p e \\
\text { hole }\end{array}$ & through & Died & Died & Died & $\begin{array}{l}\text { Ill for } 1 \text { week, } \\
\text { then recovered }\end{array}$ \\
\hline
\end{tabular}

IV. If monkey $d$ 's example is one to be followed for man, it would mean that at least two doses of 250 c.c. and 300 c.c. respectively of the emulsion would be required to produce immunity (taking a monkey's weight to be 6 kilos and the weight of a man 60 kilos). Three monkeys were also treated respectively with 100 c.c. of serum prepared in (a) Kolle's Laboratory, (b) the St Petersburg Laboratory and (c) L'Institut Pasteur in Paris. Only one survived the inhalation experiment, namely, the one treated with the Paris serum.

In a series of experiments, strains of Bacillus pestis from Mongolia (1898), Odessa and Bombay - all bubonic cases-were used for inhalation experiments. Death from pneumonic plague resulted, thus proving the similarity of the micro-organism in both types of the disease.

In another series, the experiments were reversed. Strains from Harbin and Mukden (pneumonic cases) produced the bubonic type of plague when inoculated subcutaneously.

V. Some weeks previous to my visit in July, Zabolotny had persuaded the authorities to allow cremation of all bodies dead from Plague which had been buried at Harbin during the previous winter, including those of the Doctors and Sanitary Staff. From 15 of these he removed the heart's blood for cultures and examination purposes. Results positive for Bacillus pestis were obtained in 10 out of 15 cases, including those of three doctors and two students. The soil surrounding the coffins, $2 \frac{1}{2}$ metres deep, was still frozen. These bodies were afterwards cremated and the ashes laid back again.

VI. A Tarbagan caught on June 24th by Dr Issaief near Scharasone on the Siberian side of the border was suffering from 
Plague, and died soon afterwards. Zabolotny showed me the organs of this animal. There were marked signs suggesting Plague in the spleen, lungs (hæmorrbages) and there were cervical buboes. Growths obtained from the organs gave pure cultures. From one of the cultures thus obtained, Zabolotny inoculated in Harbin a healthy Tarbagan on the right leg and produced two large buboes in the right groin only. 'This animal died of septicæmia.

VII. Four other Tarbagans were suspected to have died of Plague. These had been found:

(a) near Scharasone also by Issaief and Zabolotny,

(b) at Arabulak south of Charbada (Mongolia) by Bissemsky,

(c) at Kulussutai in Transbaikalia by Krestovsky,

(d) at Borsja (121 versts west of Manchouli) by Bissemsky.

At the time when I met Zabolotny the diagnosis of these four cases was not complete. Later, however, it was found that none of the cases were Plague.

VIII. During July, Zabolotny had received reports of large numbers of Tarbagans dying north of the River Borsja in the neighbourhood of Kerulen. We decided to equip a joint scientific expedition and visit the spot without delay.

\section{Wokк at BoRsJa. July 22nd-29th, 1911.}

\section{(Plate VII.)}

Borsja (Siberia) is 121 versts west of Manchouli on the Railway and is the centre of Tarbagan hunting in the Transbaikal district. During our stay there, no hunting was being carried on as this had been forbidden. There were some 200 to 300 Chinese engaged in small business; usually these depended on the Cossack hunters.

On the morning of July 22nd we arrived at Borsja, and joined Professor Zabolotny and his staff. The accommodation consisted of three railway cars:

(a) a car fitted up for our living quarters;

(b) a laboratory car fitted up with incubators, sterilisers, etc., and having a compartment in which post-mortems on animals were to be performed;

(c) an animal car containing about 40 cages in which Tarbagans could be kept for observation. These cages were mostly oblong and were made of thin iron sheets and ventilated by means of round apertures punched in their sides. 
Special permits to hunt were given to skilled Russian hunters who were specially instructed to bring in any sick Tarbagans. For healthy animals we offered one rouble and for sick ones five roubles.

Forty Tarbagans were kept for observation in the cages; when we had satisfied ourselves that they were perfectly healthy they were released and others put in their place. In this way about 80 Tarbagans came under observation. During the week we spent at Borsja, no sick Tarbagans were brought in and none of those under observation showed any sign of disease. On the day of our arrival at Borsja we performed post-mortems on five Tarbagans and found all of them healthy.

Prof. Zabolotny, Dr Ch'en and I drove in carts and also walked over the whole neighbourhood, visiting particularly the places where sick and dead animals were reported to have been found in large numbers.

On July 24th we drove to Tschintansk, a village south-west of Borsja. There were plenty of Tarbagans on the way and we stopped and examined the country at different stages of the journey, but could find no trace of sick animals.

The driver of our $d r o s k y$ had been in these parts for the last 27 years. He informed us that as early as 1884 Tarbagans had died from an epidemic in this neighbourhood and that one day a Russian doctor and his dresser, stationed at Akscha, performed a post-mortem examination on a hunter who had died under suspicious circumstances. They were both taken ill, and two days after performing the post-mortem, died in this man's drosky whilst trying to get back to Akscha. He remembered that both were exceedingly short of breath. Unfortunately for the veracity of this account, our isvostchick was very fond of vodka as we experienced after leaving Tschintansk-he driving very recklessly, and eventually dashing up a high bank and upsetting the carriage on the top of us! From Tschintansk we went to Arabulak-a "village" consisting of one solitary post-house and looked after by a Cossack family. Here we stopped overnight. The country between Tschintansk and Arabulak as well as the high bills surrounding the latter place abounded in Tarbagans. Our party divided up and we inspected hundreds of holes but found no trace of sick or dead animals-not even Tarbagan remains being seen.

On the following morning we got up at 4 a.m. to see if the Tarbagan came out from its hole at dawn seeking food as some believe to be the case. But during the next six hours we did not see more than five Tarbagans. We then returned to Borsja. 
In the afternoon (July 25th) we went out all around the neighbourhood of Borsja, and although we inspected many holes, no trace of a sick animal was found. On July 27 th a dead Tarbagan was found four versts away. We judged the animal to have been dead some 48 hours. The lymphatic glands were dark in colour but not enlarged, whilst the spleen was double its normal size. Full bacteriological examination, however, did not reveal any Bacillus pestis.

On July 29th we all returned to Manchouli, it having been decided that the Chinese Expedition should pursue further investigations in Mongolia. While at Borsja we performed experiments to try and ascertain if cannibalism was common among Tarbagans. In one of these an animal was starved; after some days a dead animal was introdnced into the same cage but at the end of five days the carcass had not been mutilated. I wish to take this opportunity of expressing my indebtedness to Prof. Zabolotny for his unfailing courtesy on all occasions when I had the pleasure of being associated with him.

\section{Manchovli. July 29th-August 3rd, 1911.}

After our return from Borsja to Manchouli Dr Adolphe, surgeon to the Railway, informed me on August 1st that three dead bodies had been found eight days previously some seven versts from the town. Having obtained further particulars from the President of the Russian Municipal Council, accompanied by Dr Adolphe I visited the spot. The way was past the old burial ground where six Russians and 400 Chinese dead of the Plague epidemic during the last quarter of 1910 had been buried in a long $U$-shaped trench six feet underground. After prolonged search we came across some human remains about two miles from the burial ground. The remains consisted of one skull, the bones of the thorax and a few bones of the limbs; in addition rags and clothes were scattered about. There were also planks-the remains of coffins-and three holes where these coffins had evidently been buried. There were also inscriptions in Chinese, from which we learnt that the men were Chinese and had died on the 14th, 15th and 21st of the eleventh Moon (about the end of November)-this corresponding to the period when Plague was prevalent at Manchouli. On the following day, accompanied by the Chinese Prefect, I returned to the place and after a further search found some more bones but no skulls. We collected the remains trgether, burnt them, and buried the ashes. Slides and cultures taken from the flesh still adhering to the skulls revealed no Bacillus pestis. 
VII. Work IN Mongolia. August 4th-13th, 1911.

On August 4th we left Manchouli for Mongolia. Our party and equipment consisted of :-

Three medical men-Drs Ch'en, Tsang and myself ;

One Interpreter who spoke Russian, Mongol and Chinese ;

One Sergeant and six mounted Policemen (Chinese);

One Finn Tarbagan hunter; this was the hunter who caught, in the previous April, the 12 Tarbagans for the International Plague Conference ;

Two carriages;

Three carts for tents, baggage, provisions, etc.;

Nineteen horses and ponies.

Our laboratory equipment consisted of two microscopes, media ready for use, traps and snares for Tarbagans, cages, apparatus for experiments with fleas, etc. The weather was good all day and in the evening we encamped at Tarbagan $\mathrm{Ta} \mathrm{Hu}, 30 l i^{1}$ south-west of Manchouli. The water in a lake close by was briny and we had to depend on the stock brought with us. Here swarms of mosquitoes were encountered.

\section{Mosquitoes.}

Tarbagan Ta Hu, 30 li south-west of Manchouli, August 4th, 1911, near a small lake of briny water.

Mosquitoes present in enormous numbers, the air being black with them. The gauze covers around our hats were of no avail as the insects covered them making it impossible to see, and owing to their having long proboscides they were able to attack the face. I collected some hundreds of mosquitoes and found them to be:-

(1) Culex principally, and

(2) Anopheles maculipennis.

(These were afterwards confirmed by Professor Nuttall of Cambridge.)

Later I found that the Mongols complained of fever, and since Anopheles was present in this neighbourhood, one presumes the disease to be malaria. Some Mongols seen during our expedition were suffering from what was undoubtedly malaria clinically, and the disease responded to treatment with quinine.

$$
1 l i=\frac{1}{8} \text { mile. }
$$




\section{Charbada.}

On the following day, August 5th, we reached Charbada-a village 63 li south-west of Manchouli. The country en route showed nothing but long grass and Tarbagan mounds. The village is made up of a few huts occupied by about 20 Mongol families numbering under 100 souls. As soon as the grass has been cleared by their large droves of horses, cattle, and sheep, they move their dwellings to other places. (For our observations on the Mongols, see p. 259.)

From enquiries made among these Mongols, I learnt that there had never been any outbreak of disease resembling human plague in their midst. Nor could I obtain any word of disease among the Tarbagans : the country in which they had lived for many years past abounds in Tarbagans, yet they had never noticed the animals dying.

We ourselves laid traps and caught several Tarbagans, but none of them showed any signs of disease. We scoured the neighbourhood for remains of the animal, e.g. bones, skulls, carcasses, but could find none. Leaving Charbada we made our way backwards along the banks of the River Kerulen, and arrived at Kulun See--a large shallow lake of semi-alkaline water. On the way we found many good camping grounds where there was fresh water. At many such places we found collections of Tarbagan skeletons, each numbering from 50 to 80 sets of bones, lying in heaps-evidently the remains of animals which had been skinned by the hunters who had afterwards thrown away the carcasses. At Kulun See we camped with another colony of Mongols. Here again we could get no history pointing to Plagne either among the Mongols or among the Tarbagans. In the country around, although plenty of Tarbagan holes were met with, few of the animals were seen, and our traps seldom caught any. The country had been used for pasturage by the Mongols and large stretches had been fired. From this it would seem probable that, when food becomes scarce in one region, the Tarbagans migrate to regions where food is plentiful.

From Kulun See we proposed to go to Abagaitui (Siberia) by way of Dalai Nor ${ }^{1}$, but our guide informed us this was impossible as it would mean crossing mountains where there was no water. We, therefore, returned to Manchouli, reaching there on August 31st.

1 Dalai Nor is a village 28 versts east of Manchouli and contains a coal mine supplying coal to the Railway. 


\section{The Mongols.}

$$
\text { (Plate VII, fig. 4.) }
$$

At Charbada and ,Kulun See we camped with Mongols and thus had opportunities of studying them and their habits. The Mongols at Charbada were apparently quite wealthy though they lived in a most primitive way.

The huts are round and domelike measuring about 15-20 ft. in diameter and consist of a series of moveable wooden frameworks $4 \frac{1}{2} \times 2 \mathrm{ft}$. in size, oblong in shape, and covered by felt matting made of camel's hair or sheep-skins. On the floor is laid felt matting on which the inhabitants sleep. The furniture consists of a few wooden chests where clothes and money are kept, a Buddhist shrine, a cooking pan and stove, and a box containing dried cattle-dung which is used as fuel for cooking and heating purposes. The same pair of tongs used for the dung is employed in their cooking operations.

The Mongols drink a large quantity of cow's and goat's milk and they eat, besides mutton, a good deal of Tarbagan flesh which is only half roasted before the primitive fire. There were some children in the camp at Charbada; these, and likewise the children seen at Kulun See, were clothed in rags and were indescribably dirty. All the people looked healthy, however, in spite of their peculiar mode of living. The Mongols are a simple contented people. They informed me that if more than one son were born in a family the other sons must become lamas (priests). Hence the population has decreased enormously during the last 200 years. While the men tend their flocks, the women look after the homes. A large percentage of those whom we encountered had passed their 60th year, and one old man was at least 80 . Doubtless the open air existence with the dry atmosphere preserves these people remarkably well in spite of the trying weather, but at an early age their faces show signs of toil. They were very hospitable and willingly supplied us with milk for which they declined to be paid. Their carts appeared crude and rickety, having no metal rims around the wheels, or metal work at the joints: yet they seemed to answer the purpose well. 
VIII. The Tarbagan or Marmot. (Arctomys bobac, Schreb.)

$$
\text { (Plates VIII-X, figs. 5-9.) }
$$

The Russians call this Marmot "Szuriok" and the Chinese "Han T'a"; but the name most familiar is the one adopted by the members of the International Plague Conference, namely "Tarbagan"-a term derived from the Mongols.

The Marmots belong to the group of simple-toothed Rodents which include Squirrels, Rats, Mice and Porcupines.

The particular species of Marmot found in Manchuria and Mongolia is identified as Arctomys bobuc, Schreb. (or the true Marmot).

The following are some of its distinguishing features:-

1. The body is stout and the limbs are short.

2. The tail is bushy and comparatively short, being about one balf the length of the body.

3. The head is wide and short and there are no cheek pouches.

4. The eyes are large and full.

5. The ears are small and more or less rounded.

6. Of the five toes, the thumb is rudimentary, being supplied with a flat nail, whilst the claws of the remaining four are long and exceedingly sharp.

7. The rows of molar teeth are placed nearly parallel to each other, both in the upper and lower jaws.

8. The fur is of moderate length and of a fine texture. The general colour tends to change at different seasons of the year, varying from a light greyish brown in the spring to a reddish brown hue in the late autumn. On the back and around the eyes the fur is darker in colour.

9. The length of the adult animal exclusive of tail varies from $\mathbf{1 5}$ to 18 inches (37 to $45 \mathrm{~cm}$.).

10. The weight of the adult animal varies from 9 to $12 \mathrm{lbs}$. $(4100$ to 5400 grammes), being greater as the hibernating season approaches.

After returning to Manchouli from Mongolia, a series of morning and evening temperatures were taken on these animals by us (see Appendix I, pp. 278, 279). The temperature taken per rectum presented wide variations in different animals and in the same animal at different times-even in apparently perfect health. Thus, in some it was found to be $95^{\circ} \mathrm{F}$., in others $96^{\circ} \mathrm{F}$, in others again $97^{\circ} \mathrm{F}$, and so on until in one animal $107 \cdot 6^{\circ} \mathrm{F}$. was registered. This last case was particularly interesting in that this 
temperature was obtained soon after capture. It died, however, 20 minutes after the temperature was taken and 61 minutes after capture. At the post-mortem nothing abnormal was found. In one of the animals the temperature varied from $98.5^{\circ} \mathrm{F}$. to $104.8^{\circ} \mathrm{F}$. within the space of three days.

\section{Distribution of the Marmot.}

The Marmot inhabits a wide range but is confined to the Northern hemisphere. In North America the common species is the Woodchuck, the distribution of which is from the Carolinas northward to Hudson's Bay, and westward from the Atlantic Coast to Missouri, Iowa, and Minnesota; but other species are met with in the Rocky Mountains and in the north-western parts of America, even as far as the Arctic Regions.

In the Old World, the best known species are the Bobac (Arctomys bobac, Schreb.) and the Alpine Marmot (Arctomys marmota). The region of the former extends from the south of Poland and Galicia over the steppes of Southern Russia and the bare regions of Siberia to Northern Mongolia, North-West Manchuria, the Amur Regions, and on to Kamstchatka, whilst it is found in elevated regions as far south as Cashmere, Thibet, and the Himalayas, but the southern limits have not been defined accurately. The Alpine Marmot is confined to the higher regions of the Alps, Pyrenees and the Carpathians. A small species-Spermophilus citellus, Linn.-is found in abundance in South Manchuria, especially around the neighbourhood of Mukden. This species bears little resemblance to Arctomys bobac.

\section{Habits of the Tarbagan.}

In the regions where the Tarbagan abounds, it can easily be seen either running about on its four legs or standing on its mound near the entrance to its burrow. It can be made out without difficulty in the distance as the immediate neighbourhood of the entrance to its burrow and part of the mound is devoid of grass, due no doubt to its constant presence there and to its having eaten away the grass. One or more animals may be seen resting on one mound, sometimes on all four limbs, but more often on the hind legs, the fore paws being raised with the palms turned forwards. They like the sunshine and seem to enjoy nature, uttering a noise, when at ease, similar to "pi ah, pi ah"; this has been likened to "pu p'a, pu p'a," which in Chinese means " no 


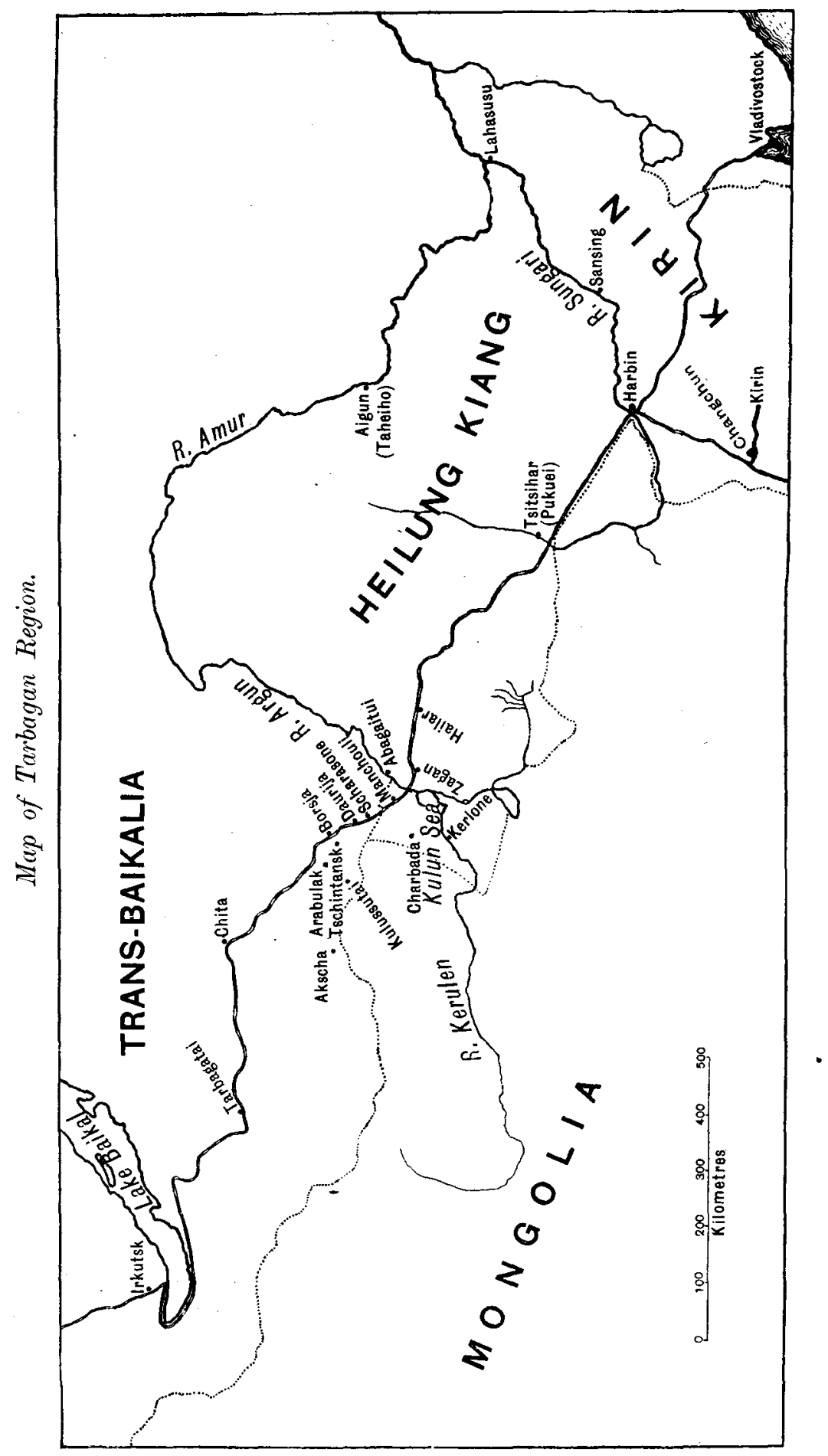


harm, no harm." The ears are very sensitive to touch but hearing is not as acute as in hares, and hence they make more use of their eyes for the detection of any possible foe. On the approach of a stranger they let fall the front paws, and immediately retire into the burrows, to come out again as soon as they feel the danger is past. When running a considerable distance their action is like that of the rabbit. When frightened they utter a cry similar to a child's "eh eh!" The Tarbagan in captivity is a very fierce animal, using his front teeth freely and biting deeply those who come in his way. With his sharp claws he scratches effectively when carelessly handled. For dealing with those we had in cages, strong forceps of considerable length had to be made, each blade curved so as to give a firm grip on the neck or body (see PI. XV, fig. 19). When placed in a wooden cage lined with parallel bars of soft iron, $\frac{1}{2}$ inch in diameter, the animal escaped in a very short time by bending the iron rods with his strong jaw and by biting the wood of the cage with his sharp teeth. An adult person was unable to bend such a rod.

\section{Habitat.}

The Tarbagan regions of North Manchuria and Siberia are well seen from the windows of the Trans-Siberian trains between Hailar and Manchouli, extending for a distance of 650 versts. The characteristic mounds are present everywhere, especially to the rorth of the line, and not uncommonly the animals are visible sitting outside the entrances to their burrows.

The holes are sometimes single, sometimes multiple, and on one mound as many as eleven have been counted by us. When occupied, the tops of the mounds are usually bare, whereas grass grows abundantly around the openings of deserted burrows. Hunters informed me that in winter when grass is absent, and the animals are hidden inside their burrows, they detect them by the peculiar smell given forth. I myself tried to detect the odour, and was satisfied that it was characteristic. The presence of innumerable mounds, or "bootans" as the Russians call them, is very distinctive of the Tarbagan country, where the land presents a series of undulations, over some of which the grass grows to an unusual length (Pls. X-XIV, figs. 10-18). These mounds have been made from the earth thrown up by generations of Tarbagans in the course of their digging operations. Where the mountains are of rocky formation, as at Arabulak in Siberia, large pieces of stone, some weighing as much as two pounds, were seen lying at the entrance of the burrows; these 
had evidently been dug up by the animals whilst making their burrows, and showed the great strength of their paws. In other parts, however, the land is more sandy in nature, and beyond their raised appearance they present no great variations. The entrance to the burrow is funnelshaped, and ranges from $1 \frac{1}{4}$ to $2 \frac{1}{2}$ feet in diameter. At the entrance twigs and seeds are often found, probably the remains of food, and also hard faecal matter. The tunnels vary from $\frac{1}{2}$ to $1 \frac{1}{4}$ feet in diameter becoming narrower as they are traced inwards. When two holes are, say, 12 feet apart, a straight connecting path may be seen where grass has not grown, thus showing that frequent communication takes place between the animals. From the entrance, a sloping passage 5 to $6 \frac{3}{4}$ feet (150 to $200 \mathrm{~cm}$.) long leads to a horizontal, more or less zigzag tunnel, the depth of which is $3 \frac{3}{4}$ to $5 \frac{1}{2}$ feet (110 to $180 \mathrm{~cm}$.) from the surface. Along this underground passage there are specially widened spaces, at some of which faecal matter is deposited, whilst at others there are stored dry grass and twigs-apparently the living quarters of the animal. Very often, when other entrances are traced, they are found to lead to a common passage, so that at places a series of subterranean tunnels extending for hundreds of yards may be said to exist. It is interesting to note that in the course of our digging operations the skulls and bones of Tarbagans were found in the passages, showing that in past times Tarbagans had died in their subterranean homes. Considering that the ground in North Manchuria and Mongolia is frozen in winter to over six feet deep, the Tarbagan may be said to pass through his long hibernating period well within the freezing zone, as the burrows seldom reach a depth of 5 feet. Some of these burrows end blindly after a distance of 4 feet $(120 \mathrm{~cm}$.), but others communicate freely. This was instanced by the fact that traps laid for days outside one opening did not catch any animal, and stones placed by us to block an entrauce did not affect his peregrinations (Pls. XIII-XIV, figs. 16-18).

Regarding breeding, there is reason to believe that the Tarbagan is not as prolific as the rabbit-two or three being the average number of young ones born each season. When the young are old enough to look after themselves, the mother leaves them in the old burrow and digs a new one for herself. Many half completed burrows were met with in the summer of 1911 during the course of our journey. The new burrows in some cases led to old "earths." 


\section{Hibernation.}

The Tarbagan hibernates from October to April ; at the end of September 1911 the weather was becoming cold at Manchouli and Dr Ch'en noticed that some of the animals in the cages began to curl up preparatory to hibernation. In winter the cold is very severe, the thermometer marking $-30^{\circ}$ to $-40^{\circ} \mathrm{C}$. Indeed, Marmots seem to be the most thoroughly hibernating of all mammals, since their sleep is apparently unbroken, and they lay up only a small store of winter food, consisting of grass, roots and the seeds of plants. Whilst in this stage they are utterly helpless. In March, 1911, before the cold season had passed away, twenty-four Tarbagans were dug out from their several burrows in the neighbourhood of Manchouli. They were found lying in the nests of soft herbage far away from the openings of the burrows. For some time, however, after their retirement they continue active within their domicile and feed upon the food which they have gathered during the summer; and as a preparation for their winter sleep, they become exceedingly fat during the autumn. With the return of spring comes renewed activity on the part of the animals, and they venture into the open. Hence the hunters choose the months of April, May and June for hunting them. July and August is the breeding season, and the Chinese authorities forbid trapping during these months. After August they are again hunted until the approach of cold weather -about the end of September.

\section{Method of catching the Tarbagan.}

The method generally adopted by the Cossack and Chinese hunters for catching Tarbagans is simple in the extreme. A piece of mediumsized iron wire, $2 \frac{1}{2}$ feet in length, has one end twisted in the form of a running loop, whilst the other end is wound firmly round a rough wooden peg $\frac{3}{4}$ foot long (Pl. XV, fig. 19). The peg is driven into the ground immediately above or on the side of the entrance to the burrow, and the loop is arranged so that it fits exactly into the opening. When the animal comes out, the head and probably also one of the front paws are caught in the loop. The more it struggles the tighter the snare becomes, and in this state the hunter finds the animal when he returns from his rounds. Sometimes, double loops are attached to a single peg in order to obtain a more secure hold of the animal. The cost of the complete snare is only two copper cents (about one half-penny). In our 
own experience the snare proved to be the most successful means of catching the Tarbagan. The hunters informed me that on lucky days they could catch from five to six animals, which meant an earning of 4-5 roubles a day (counting the price of each skin at 80 kopecks).

\section{Method of killing and skinning.}

After capture, the animal is killed by a method called "breaking the neck." The animal is seized by the hind legs, a stick or bar of wood is placed on the back of the neck with one foot at either end of the stick, and then the animal is pulled backwards and upwards. This quickly dispatches the creature, and saves the fur from being soiled with blood. From enquiries made it appears that skinning is not done on the spot, but only when the hunters have gathered again in their common camp -frequently after two or three days' absence. Skinning is performed by incising the two corners of the mouth, separating the skin from the soft parts of the jaws and then pulling the complete skin from before backwards and from within outwards, i.e. the skin is turned inside out. As previously noted, when travelling in Mongolia, isolated heaps of Tarbagan bones were often seen-evidently the remains of carcasses left after the animals had been skinned. The raw skins or "pelts" are dried, collected together, and put aside until the end of the hunting season, when they are brought by the hunters to the markets of Borsja (Siberia), Manchouli, and Hailar ${ }^{1}$ (North-West Manchuria), and sold to dealers-usually Russian Jews.

\section{The Tarbagan in commerce.}

The trade in fur has been fully dealt with already (see pp. 251, 252). Besides using the fur, the Siberian settlers and Mongols eat the flesh of the Tarbagan (see p. 259). When at Charbada the members of our party partook of the flesh and found it tender and the taste distinctly good, comparing favourably with the flesh of the rabbit. Considerable quantities of the flesh are salted and exported to European Russia.

In addition, the fat, which is plentiful under the skin of the animal, is turned into a valuable kind of grease much used by Russian peasants for preserving leather; they also apply it for the healing of bruises.

${ }^{1}$ Borsja is 121 versts west of Manchouli. Hailar is 174 versts east of Manchouli. 


\section{The Tarbagan in captivity.}

Cages (Pl. XV, fig. 20). For keeping the animals we used both single and double cages made of thin iron plates. These had doors in front and behind so as to facilitate cleaning and the transference of the animals from one place to another. The sides were perforated with a few round holes for ventilation. Rods and parallel slits were found impracticable, as the animals easily damaged them and sometimes escaped. For experimental purposes single cages were made with a glass front to allow of observation.

We originally took with us from Harbin a few cages made of wood, one inch thick, and provided in front with soft iron bars half-inch in diameter; but the animals quickly destroyed these, gnawing away the wood and bending the bars.

In Mongolia and Manchouli it was found, as indicated elsewhere in this Report (Appendix I, pp. 278, 279), that Tarbagans often died when kept in close captivity. In March 1913, i.e. the end of winter, 13 animals were dug up while still hibernating and placed in cages. Within ten days two had died and before five weeks had passed, four more succumbed. Two Tarbagans presented in 1911 to the Zoological Gardens in Peking were kept on earth in a spacious pen; after a year they were still alive and healthy. We propose therefore to adopt a similar plan for keeping these animals in future.

For food, hay, cabbage, carrots, and ground nuts have been found satisfactory; a pan of water in the cage does not seem necessary.

\section{Forceps for handling the Tarbagan.}

It was some time before we found the most convenient and suitable type of forceps to use in handling Tarbagans. The pair of forceps eventually employed (Pl. XV, fig. 19) is made of stout wrought iron, 20 to 22 inches long, and thickest at the handle. The blades used at the end for gripping the animal are curved to form an oval $\left(4 \frac{1}{2}{ }^{\prime \prime} \times 3 \frac{1{ }^{\prime \prime}}{}\right)$ - this being large enough to take hold of the neck or body without injury. Distal to the oval the blades are prolonged parallel to each other for a distance of half-inch and are there rounded off.

\section{Parasites of the Tarbagan.}

In its natural state the Tarbagan harbours two kinds of blood-sucking arthropods, namely the flea and the tick. The fleas were more numerous on the animal when freshly caught than after it had been in captivity 
for some time. Most of the fleas were caught in the groins, but of ten they were distributed over the whole body. The ticks were usually attached to the eyelids, but on one occasion we found two ticks on the abdomen and none on the eyelids. The number of fleas per animal varied greatly even just after capture. For example, we caught 94 fleas on a Tarbagan at Charbada ; the fleas on Tarbagan No. XVIII (see page 279) were noted as numerous; on Tarbagan XXIII, three days after capture, no fleas were found but only four small ticks and one large tick; on Tarbagan XXVIII (see page 279) two fleas and two ticks were found. All the fleas were of the same species, namely Ceratophyllus silantievi, Wagner 1898. I append a short description taken from those we collected.

\section{Fleas.}

Ceratophyllus silantievi (Pl. XVI, fig, 22). An eyed, single-combed flea of large size. Of six males, the shortest was $1.97 \mathrm{~mm}$. long, the longest $2 \cdot 34 \mathrm{~mm}$, whilst the average length was $2.2 \mathrm{~mm}$; of 13 females the shortest was $1.48 \mathrm{~mm}$., the longest $3.07 \mathrm{~mm}$., whilst the average length was $2.82 \mathrm{~mm}$. The eye is small and the antennae are well developed; the base of the antenna is situated at some distance directly above the eye, and the antenna when lying in the groove is directed downwards and backwards. There are three bristles, one in front of the other, anterior to the eye. The maxillary palps and mouth parts (epi-pharynx, mandible, labium) are long and well developed. Springing from the posterior border of the first thoracic segment is a comb consisting of nine bristles on either side. The mesosternite has a vertical thickening (bar). The inner aspect of the femur is studded with numerous hairs. The posterior border of the hind tibia presents six pairs of bristles. The last joint of the tarsus has six bristles on either side and the claws are fairly long. There are nine bristles inserted on either side near the posterior border of the tergal plates. The antepygideal bristles are three in number on each side.

Biting experiments with Fleas and Ticks obtained from the Tarbagans.

The insects were removed from the Tarbagans directly the animals were caught and were placed in test tubes.

The following experiments were carried out by us when in Mongolia and later on our return to Manchouli. As will be readily understood, the conditions did not permit of detailed and prolonged experimentation 
and this record is given merely as a preliminary communication on the subject.

Experiment 1. When at Charbada, some six fleas in a test tube, immediately after their removal from the Tarbagan, were given the opportunity of biting one of us. Even after several minutes none of them had bitten.

Experiment 2. August 10th, 1911. Ceratophyllus silantievi, $1 \delta$. Starved for three days. Then given facilities for biting the arm of one of the party. The insect moved about for some minutes before biting. It chose a spot in a fissure of the skin and plunged its proboscis deep in. While sucking its body was tilted upwards and the insect was seen to increase in bulk. It remained thus for eight minutes and then, having withdrawn the proboscis, fell on its, side. Afterwards it began moving around less actively than before.

The person bitten experienced no pain and very little sensation both when the flea pierced the skin and during the time the insect was sucking. After the flea had withdrawn its proboscis, the site of the puncture was barely visible to the naked eye and with the aid of a hand lens a very slight escape of blood was seen to have taken place from the puncture. There was no after swelling or irritation.

Experiment 3. August 14th, 1911. Ceratophyllus silantievi, 1 d. $1 q$, having being starved for some days, were placed on the arm of the police sergeant. Both behaved in a similar manner to the flea used in Experiment 2. After sucking for 10 minutes and before they had withdrawn their proboscides, the experiment was accidentally distnrbed and the fleas fell to the ground. In this case also no after irritation occurred.

Experiment 4. August 14th, 1911. Ceratophyllus silantievi, $1 \delta^{7}$, having been starved for four days, was allowed to bite the arm of one of the servants. The insect moved around for about five minutes and then, choosing a fissure of the skin, inserted its proboscis. At first the body of the flea remained in the horizontal position while the distal portion of the proboscis was inserted. Gradually the proboscis was buried completely and by that time the flea's body had assumed the more or less vertical position. As in the preceding experiments, there was an almost complete absence of after-effects.

The Ticks (a species of Rhipicephalus ${ }^{1}$ ) were collected in test tubes and similar experiments to those with the fleas were carried out. In no case did a tick bite the arm of a human being, although the tick used in one experiment had been starved for eight days.

$$
1 \text { ? R. haemaphysaloides, nymphs. }
$$




\section{iX. Susceptibility of the Tarbagan to anthrax.}

Anthrax is a disease very common in Siberia where it attacks both human beings and horses, it being known in the latter as the "Siberian Pestilence." After our return to Manchouli on August 14th we determined to find out whether the Tarbagan was susceptible to this disease as no experiment of the kind had been performed before.

Experiment I. Tarbagan XIV. On the evening of August 20th, 10 c.c. of a 24 hours' old bouillon culture of Bacillus anthracis were inoculated into the loose subcutaneous tissue of the back of a healthy adult Tarbagan. The animal became very ill, and on the morning of August 23rd was found curled up and lying on its side dead.

The temperature recorded was as follows:-

$$
\begin{array}{rlr}
\text { August 18th, } & \text { E. } & 98 \cdot 6^{\circ} \mathrm{F} . \\
19 \text { th, } & \text { E. } & 101 \cdot 7 " \\
20 \text { th, } & \text { M. } & 99 \cdot 8 " \\
& \text { E. } & 98 \cdot 4 "
\end{array}
$$

10 c.c. bouillon culture of $B$. anthracis injected.

$\begin{array}{lll}21 \text { st, } & \text { M. } & 100 \cdot 4^{\circ} \mathrm{F} \\ & \text { E. } & 102.2 " \\ 22 \mathrm{nd}, & \text { M. } & 100.8 " \\ & \text { E. } & -\end{array}$

Post-mortem Findings.

Slight swelling and marked induration around the point of inoculation. Superficial veins dilated. General venous engorgement. No petechial haemorrhages.

Lungs: very slight congestion.

Heart: coronary vessels dilated; right side of heart dilated.

Liver: enlarged and congested.

Spleen : markedly enlarged and congested.

Microscopically: Bacillus anthracis found in the heart blood, blood from superficial veins, peritoneal fluid, pericardial fluid, scrapings from the spleen and liver. No particular variation in the distribution of the bacilli was found. The organism was obtained in pure culture from the heart's blood.

Experiment II. Tarbagan XVII. On the evening of August 20th, 5 c.c. of a 24 hours' old bouillon culture of Bacillus anthracis was inoculated into the loose subcutaneous tissue of the back of a healthy adult Tarbagan. The animal became very ill and on the morning of August 23rd was found curled up and lying on its side dead. 


\section{Wu Lien-Teh (G. L. Tock)}

The following is the temperature recorded :-

$\begin{array}{rll}\text { August } 19 \text { th, } & \text { E. } & 98 \cdot 2^{\circ} \mathbf{F} . \\ \text { 20th, } & \text { M. } & 96 \cdot 8, \\ & \text { E. } & 98 \cdot 2 "\end{array}$

5 c.c. bouillon culture of $B$. anthracis injected.

$\begin{array}{lll}\text { 21st, } & \text { M. } & 100 \cdot 8^{\circ} \mathrm{F} . \\ & \text { E. } & 103 \cdot 4, \\ \text { 22nd, } & \text { M. } & 100 " \\ & \text { E. } & -\end{array}$

\section{Post-mortem Findings.}

Marked swelling and induration around the point of inoculation. Glands in neck and axilla a little enlarged and showing petechial haemorrhages: femoral glands markedly enlarged. Other appearances, the sume as in Tarbagan XIV, Experiment I.

These two experiments prove, therefore, that the Tarbagan is susceptible to Anthrax and the post-mortem findings are similar to those seen in other susceptible rodents.

\section{Investigations into Reported outbreaks of Plague AT PUK'UeI.}

When at Manchouli, it was reported in the local papers that several fatal cases of Plague had occurred at Puk'uei (Tsitsihar) in the quarter allotted to the maisons publiques. These reports gave apparently substantial details regarding such symptoms as headache, fever, coughing of blood, etc.-all pointing to an outbreak of pneumonic plague. I determined to visit Puk'uei without delay to enquire into the matter. I arrived there on August 26th. On investigation I found that two or three servants attached to the houses had recently suffered and died from acute enteritis, which could be traced to the raw fruit and iced drinks of which they had partaken freely during the prevailing hot weather. There was nothing to indicate an epidemic, and having satisfied myself fully as to these points, I left for Harbin on August 28.

It may be added here that reports of a similar kind had been circulated in Changchun, Dalny and other places. All these on investigation proved groundless.

Simultaneously with the report of Plague in Puk'uei, there came news that four deaths from bubonic plague had occurred among Russians 
at Scharasone; these cases were confirmed later on, as well as a fifth case occurring in the same village ${ }^{1}$.

\section{Susceptibility of the Tarbagan to Bacillus pestis.}

When at Manchouli, August 14th to 25th, we proposed performing some experiments on the susceptibility of the Tarbagan to Plague. Unfortunately our cultures of Bacillus pestis proved to be of an avirulent strain. Owing to difficulty of transit we were unable to obtain other strains. Hence the experiments could not be carried out.

That the Tarbagan is susceptible to Bacillus pestis has been shown by Strong and Teague, Zabolotny, Dujardin, Beaumetz and Mosny.

\section{Evidence associating the Tarbagan with Plague and CONCLUSIONS THEREFROM.}

The Tarbagan has been said to'suffer from a chronic form of plague not unlike the form seen in rats. From time to time epidemics have been reported as occurring among the Tarbagans causing them to die in thousands. It has been said that hunters easily recognise the sick animals - these often being driven out from their holes to wander about aimlessly until they die. The piteous state of these animals has been graphically described.

If a human being takes plague and has eaten of the flesh of the Tarbagan-a very common food among the Mongols and Cossacks (page 259) - it has been stated forth with that this is the source of infection. Indeed, whenever a case of human plague occurs in a remote district of the Tarbagan country, it is stated almost invariably that the disease has resulted from the eating of Tarbagan flesh. Take the following excerpt, translated from a paper issued on December 8th, 1912, as an example:-

"News has come from a village Onon-Borzinski, near Chita, to the effect that some Cossacks, three in number, had been stricken with plague and died. It appears that they had returned at the beginning of October (old style) from Zagan-Olnevski where they had been hunting Tarbagans and had brought with them some frozen Tarbagan flesh. On October 31st one of these Cossacks took ill with symptoms of fever and spitting of blood and died after two or three days' illness. The others followed."

Comment is needless!

1 Scharasone is the Russian village 30 miles west of Manchouli where Dr Issaief picked up his Plague Tarbagan in June, 1911 (see p. 254). 
Some of the epidemics referred to as occurring among the inhabitants of the Kirghiz settlements (pp. 243-247) were said to have been associated with a disease in camels, and one case of human plague was said to have followed the consumption by the patient of the flesh of a camel stricken with plague.

To quote further examples would be useless and to mention individual authors invidious.

It is my purpose to review the facts which have so far been ascertained bearing upon the relationship of the Tarbagan to the outbreak of plague in human beings. It need scarcely be said that before a diagnosis of plague is established a complete bacteriological examination must be made. It has been definitely established that rats suffer from plague and from them the disease is conveyed to man. The chronic form of plague has been found among the gophers and ground-squirrels (Citellus beecheyi) of the Western United States by McCoy. Mice and guinea-pigs are susceptible to artificial infection with Bacillus pestis. Strong and Teague, Zabolotny, Dujardin, Beaumetz, and Mosny have shown that the Tarbagan also is susceptible, and Shibayama has demonstrated that Spermophilus citellus, the small species of marmot common about Mukden (page 261), is susceptible to plague though not so susceptible as the rat.

Since these Rodents are susceptible to plague and since the disease occurs in nature among rats and ground-squirrels, $a$ priori it is conceivable that it occurs among Tarbagans in nature.

Let us examine the evidence available to establish this as a fact. An epidemic among the Tarbagans was reported in July 1911 (page 240), and the Russian and Chinese expeditions at once visited the country where this epidemic was supposed to exist. Not only did the expeditions fail to discover a single- diseased Tarbagan, but enquiries made by us directly from the hunters showed that they knew nothing of the alleged epidemic. In the experience of these hunters not only had no epidemic ever occurred among the Tarbagans but they had never even seen sick ones. In Mongolia, the Chinese expedition had similar results nor could any news be obtained of disease, past or present, from the Mongol hunters. In passing, I would emphasise that information was sought by us direct from hunters who were experienced men and who had spent their lives living and hunting in the country where the Tarbagan abounds. Moreover two of the police who accompanied us on our Mongolian expedition were formerly Tarbagan hunters; and the Finn hunter whom we took with us had been hunting regularly for the past five years and could recall no case of Tarbagan disease. 
Dr Ch'uan, in his paper at the International Plague Conference, already referred to, stated: "I had several talks with the marmot hunters and enquired whether they knew of the occurrence of any cases of sickness, such as blood spitting or of sudden death during their hunting season on the hills. They replied that they had never known of such cases either on the hills or on their return journey, and that only at Dawoolya, Manchouli or other towns did the plague attack the marmot hunters and others." The enquiries we made on this point from the hunters elicited the same information. We did not hear of any case of plague having occurred amongst them while on the plains. It is well to state here that although the Tarbagan hunters dispersed in pursuit of their business, staying away for one or several weeks, they usually reassembled at the regular camps to skin the animals captured. Moreover, although millions of Tarbagan skins were exported yearly to Europe, and thus handled by hundreds, perhaps thousands of people, from the hunter and the railway porter to the factory labourer, no case had ever been reported of plague infection in human beings during the transit of such skins. It is also very doubtful whether plague occurs as a result of eating plague infected flesh. As bearing upon this question the following may be quoted :"In many instances during the Manchurian epidemic the patient with pneumonic plague must have swallowed enormous numbers of plague bacilli in the saliva and sputum. Nevertheless, in none of the necropsies performed during the epidemic were evidences of primary intestinal infection present, nor was serious involvement of the intestine encountered. This fact certainly speaks strongly against the evidence of primary intestinal plague in man and would seem to show that even if the intestines are sometimes secondarily involved, this condition in human beings must be also a very rare one." (Strong and Teague.)

Moreover, referring to the disease in camels mentioned above, Mr Shuropof, a veterinary surgeon who investigated the possibility of this animal suffering from plague, concluded that the camel was entirely insusceptible to the disease. He thinks that the observations made in the Kirghiz steppes must be received with doubt and that possibly the organism isolated from the dead camel was the Bacillus bipolaris plurisepticus, and not the plague bacillus ( $V$ ratch, No. 52, December 31st, 1911, quoted in Lancet, March 9th, 1912, page 688).

The only definite proof that Tarbagans in nature are affected with plague is obtained from the animal caught by Issaief in June at Scharasone, and examined by Zabolotny (pp. 253, 254). 
To conclude that a man whose occupation is that of a Tarbagan hunter and who takes plague has been infected from a Tarbagan is comparable to concluding that a man who sells rice and who developes plague has been infected from the rice. In the latter case it is possible that the rice through the rat flea was the source of infection; but if, without some proof that this were so, the statement was made, such a conclusion would be at once condemned as unjustifiable. From the above it seems to me a pity that responsible authorities and medical men should be so obsessed with the unestablished idea of the great infectivity of the Tarbagan as to place hindrance in the way of transporting by rail live healthy Tarbagans for important scientific research at our headquarters laboratory at Harbin, an experience which I had in March of this year.

\section{Conclusions.}

1. Even though the Tarbagan occasionally suffers from Plague, the epizootic is never extensive, and the animal does not play nearly so important a rôle in the spread of Plague as does the Rat. Indeed its direct relationship to human plague may be considered negligible. Moreover, the mode of living and habits of the Tarbagan are very different from those of the Rat: for example, while the Rat is a more or less domestic creature in close contact with man, the Tarbagan is the reverse.

2. From the writings of Russian authorities, it appears that Plague has existed for many years in various parts of Siberia, sometimes in the bubonic form, sometimes in the pneumonic form. These places may be looked upon as endemic foci. In 1910 it is believed that pneumonic Plague appeared in the Russian Ural District long before it made its appearance at Manchouli and developed into that great Manchurian epidemic. During the latter half of 1911 this form of Plague was present in the Kirghiz settlements. In these districts, from October 1911 to February 1912, over 200 cases of Plague occurred. No case of Plague, in man or animal, has occurred in Manchuria since the epidemic of 1911.

3. From this report it is obvious that statements of the occurrence of Plague among men or animals should be believed only when they come from responsible sources-that is, after proper medical and scientific investigations. 


\section{Recommendations regarding Tarbagan Fur Trade.}

Writing from Manchouli Station on August 21st, 1911, the following were some of the recommendations I made to the Chinese Government in regard to the Tarbagan Fur Trade:

"1. That as far as this year is concerned, the Order (prohibiting the hunting of Tarbagans) should stand so as to allow the animals a chance of breeding. In a large part of the territory within $100 l i$ of Manchouli, the animals were practically exterminated last year, some 2,000,000 having been killed.

“ 2. That two central stations, say Manchouli and Hailar, should be established, with a medical staff at each place. To these stations the skins should be sent for inspection and disinfection (if necessary). After examination and disinfection (if necessary) a chop ${ }^{1}$ should be imprinted on each skin, certifying its healthy state and allowing it to be exported.

" 3. That the usual tax of roubles 6.80 , should be levied on every hunter for each season. Last year (1910) two seasons were permitted, but I would suggest only one season be permitted in future so as to preserve the animals from extinction.

"4. That whenever permits are issued to the hunters, directions (verbal as well as written) should be given for protection against possible infection, such as keeping the raw skins away from their sleeping quarters and supervising, if not establishing, lodging houses where the hunters may lead a hygienic life."

I further stated :

"In carrying out these recommendations, doubtless a few difficulties would be encountered, but I am sure the best method is to control in a rational manner the Tarbagan trade rather than to abolish it entirely. A very small percentage indeed of Tarbagans catch the disease, and supervision would be quite an easy task.

"The following are some of the advantages of effective control :

“1. The poor people will be profitably occupied and a large and increasing business will be saved from destruction.

"2. Good scientific work will be done by the doctors and hence our knowledge of Plague and of Tarbagan diseases will be increased."

1 Government mark or stamp. 


\section{Outbreak of Plague on S.S. Cheongshing.}

At the beginning of June 1912, I received instructions to enquire into some deaths from Plague which were reported to have occurred in Tientsin. I ascertained the facts to be as follows:

The S.S. Cheongshing arrived at Tientsin direct from Hongkong on the evening of May 31st, 1912.

The first purser's wife, aet. 30, died on board on May 29th, while the boat was at sea.

On June 2nd the first purser, aet. 43, complained of shortness of breath and faintness. He was diagnosed as suffering from pneumonia, and was admitted on June 3rd to a mission hospital in Tientsin; the patient died a few hours after admission. On June 4th the second purser, aet. 36, complained of tightness of the chest and cough with blood-stained sputum. He was admitted to a Government hospital with the diagnosis of pneumonia. He died early next day (June 5th). Lung puncture, performed after the death of the patient, revealed Bacillus pestis - this being confirmed afterwards by complete bacteriological examination.

The Port Health Officer did not diagnose and hence did not certify plague, and allowed the steamer to leave Tientsin on June 5th bound for Chefoo. Off Chefoo the vessel was quarantined on account of a wire from the Chinese authorities and was not permitted to approach the town. On June 8th the vessel sailed for Shanghai.

At Woosung, ten miles from Shanghai, the vessel flew distress signals as more cases of plague had occurred; one fireman and one seaman had died on June 14th. The vessel was quarantined and the crew and passengers were isolated. No further cases occurred and the steamer reached Hongkong in safety.

Later I ascertained that the female patient had lived in a house in Hongkong where two deaths from plague had occurred just before coming on board.

In connection with these cases of pneumonic plague it is interesting to observe that the wife of the first purser was supposed to be suffering from pulmonary tuberculosis. To ease the cough the second purser lent the patient his opium pipe to smoke, afterwards using it himself. In all probability the husband of the patient smoked from the same pipe, as in such cases it is customary for another person to prepare it for use. 
Whether the pipe was the direct means of conveying the infection is problematical as the trio had been in close communication in using the small ship's cabin: it is certain that the usual spread of pneumonic plague is by the direct inhalation of the micro-organism.

\section{APPENDIX I.}

\section{Rectal Temperature of the Tarbagan.}

The series of temperatures given in the accompanying table were taken at Manchouli after our return from Mongolia.

The animals were kept in cages. An animal was removed from the cage by means of the special forceps and was held resting on the ground by one of us while the other took the temperature (see Pl. XVI, fig. 21). The morning temperature was taken about 9 a.m. and the evening temperature between 3 and 5 p.m.

Often after capture by the snare the animal died, no obvious cause being found at post-mortem examination. A larger percentage of those caught with double snares died than those caught with single snares.

\section{PROTOCOL.}

Tarbagan No. XI. Healthy during the whole time the observations were taken.

Tarbagan No. XII. September 9th. Appeared sick, lying quite still and apathetic ; does not resent provocation; all limbs paralysed, unable to move when placed on back; no crying; no convulsions. Death. Post-mortem: some of the glands in neck congested but not enlarged; spleen enlarged but not congested; liver shows fatty degeneration; gall bladder distended with gas, no bile, adherent under surface of liver; small infarcts in upper lobe of right lung; pericardial sac contains more fluid than normal. Films made from the blood and organs show no micro-organism; no growth obtained in media inoculated with heart blood or from spleen.

Tarbagan No. XIII. August 22nd. Appeared ill in the afternoon. Hind limbs paralysed. Died early on August 23rd. Post-mortem: all organs normal. Films and cultures negative.

Tarbagan No. $X V$. September 9th. Paralysis of hind legs; resents provocation ; utters no cries when brought out of cage ; attempts to escape using fore legs only, hind legs being dragged. September 11th. Appears rather better, hind limbs still paralysed. September 13th. Cries when handled. September 18th. In statu quo.

Tarbagan No. XVI. Died suddenly on night of September 13th. Post-mortem showed cause of death to be a large rupture in the left lobe of the liver. Examination for micro-organisms negative (films only). 
Tarbagan No. XVIII. Caught morning of August 19th. Attempted to escape while being brought to camp in sack. $3 \mathrm{p} . \mathrm{m}$. Convulsions while lying on ventral surface; appeared to be biting at cage in attempt to escape. 4.10 p.m. Quite apathetic ; temperature 107.6 ; had convulsions while temperature was being taken; numerous fleas. 4.30 p.m. Gave a few gasps and died. Weight 10 lbs. (English). Length, tip of nose to tip of tail, $25 \frac{1}{2}$ inches $\left(64 \frac{3}{4} \mathrm{cms}\right.$.). Post-mortem: nothing abnormal found.

Tarbagan No. XIX. Young animal. August 23rd killed and cooked.

Tarbagan No. $X X$. Healthy during the whole time the observations were taken. Killed for anatomical observations September 4th. Weight 9 lbs. Length, tip of nose to tip of tail, $24 \frac{1}{2}$ inches.

Tarbagan No. $X X I$. Healthy during the whole time the observations were taken.

Tarbagan No. XXII. Healthy up to August 27 th when it showed symptoms similar to those noted above for Tarbagan XII and Tarbagan XV. Died in the afternoon. Post-mortem: organs showed similar appearances to those noted under Tarbagan XII. Smears made from the glands and organs showed bacilli which, however, were obviously not Bacillus pestis; no growth in media even after six days.

Tarbagan No. XXIII. On August 28th died suddenly without previously showing any signs of illness. Post-mortem findings similar to those of Tarbagans XII, XV, XXII. Smears similar to those from Tarbagan XXII. No growth on media even after four days.

Tarbagan No. XXIV. Healthy during the whole time the observations were taken.

Tarbagan No. $X X V$. Healthy during the whole time the observations were taken.

Tarbagan No. XXVI. Healthy during the whole time the observations were taken. On September 30th the animal curled up through cold.

Tarbagan No. XXVII. In good health up to September 7th, then did not appear to want to feed. Died on September 18th. Very emaciated. Post-mortem examination revealed a small rupture in the right lobe of the liver; adherent blood clot was present in the neighbourhood. Other organs apparently normal. Bacteriological examination negative.

Note. An animal (Tarbagan No. XXVIII) caught on August 25th died soon after being brought into camp. There were marks of severe constriction by the wires of the double snare around the neck and at the level of the umbilicus. Post-mortem examination showed no abnormal appearances. 

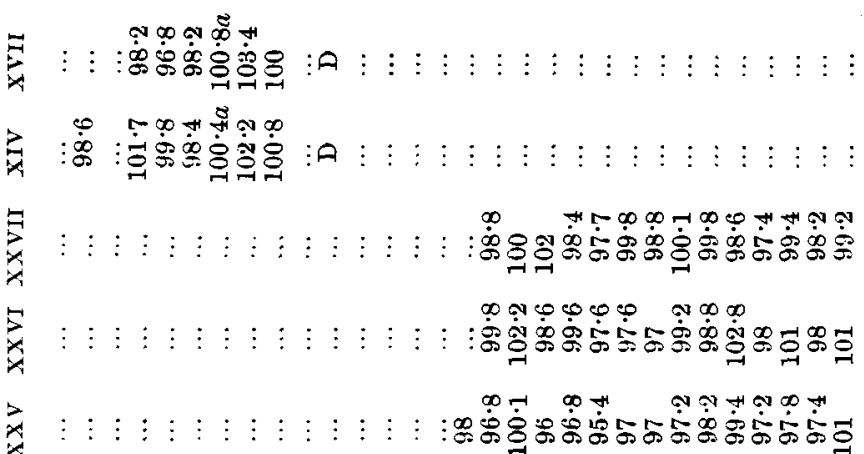

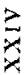

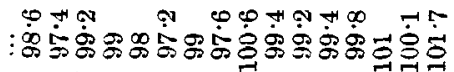

目

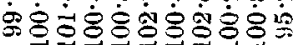

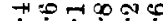

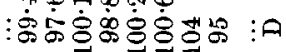

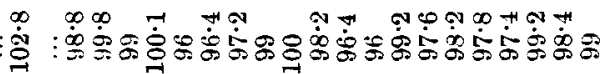

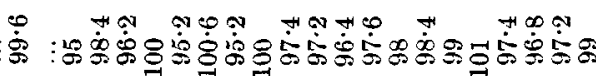

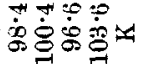

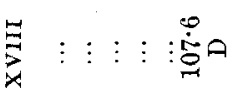

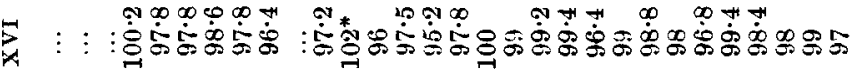

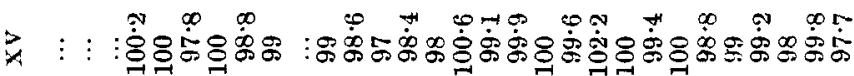

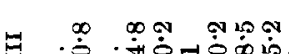

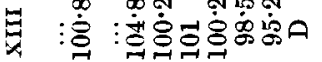

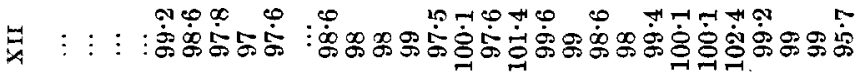

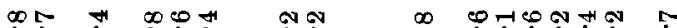
1 : : : ஃ

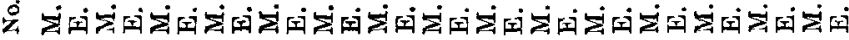
总

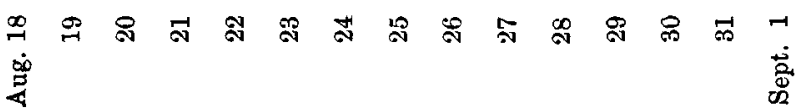




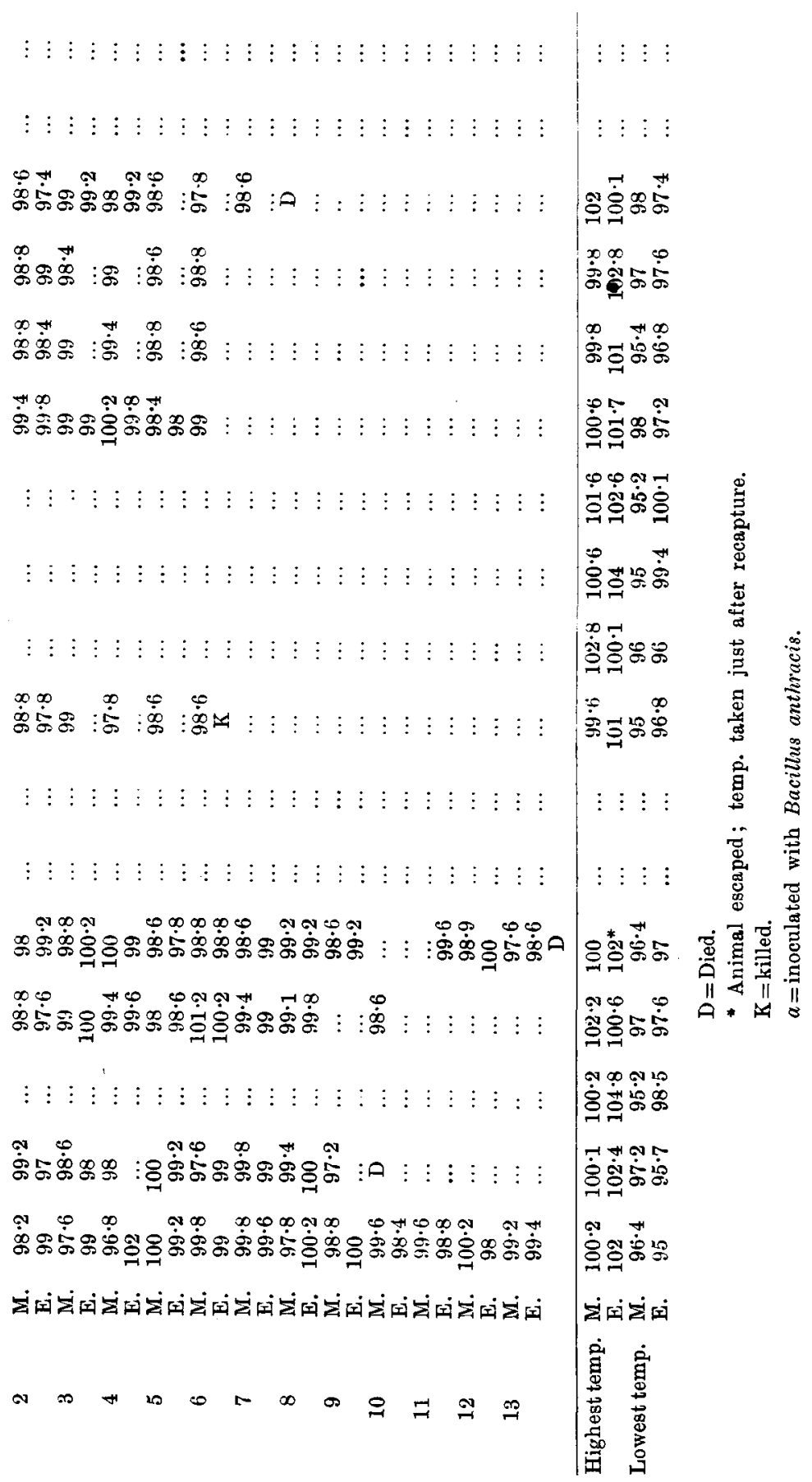




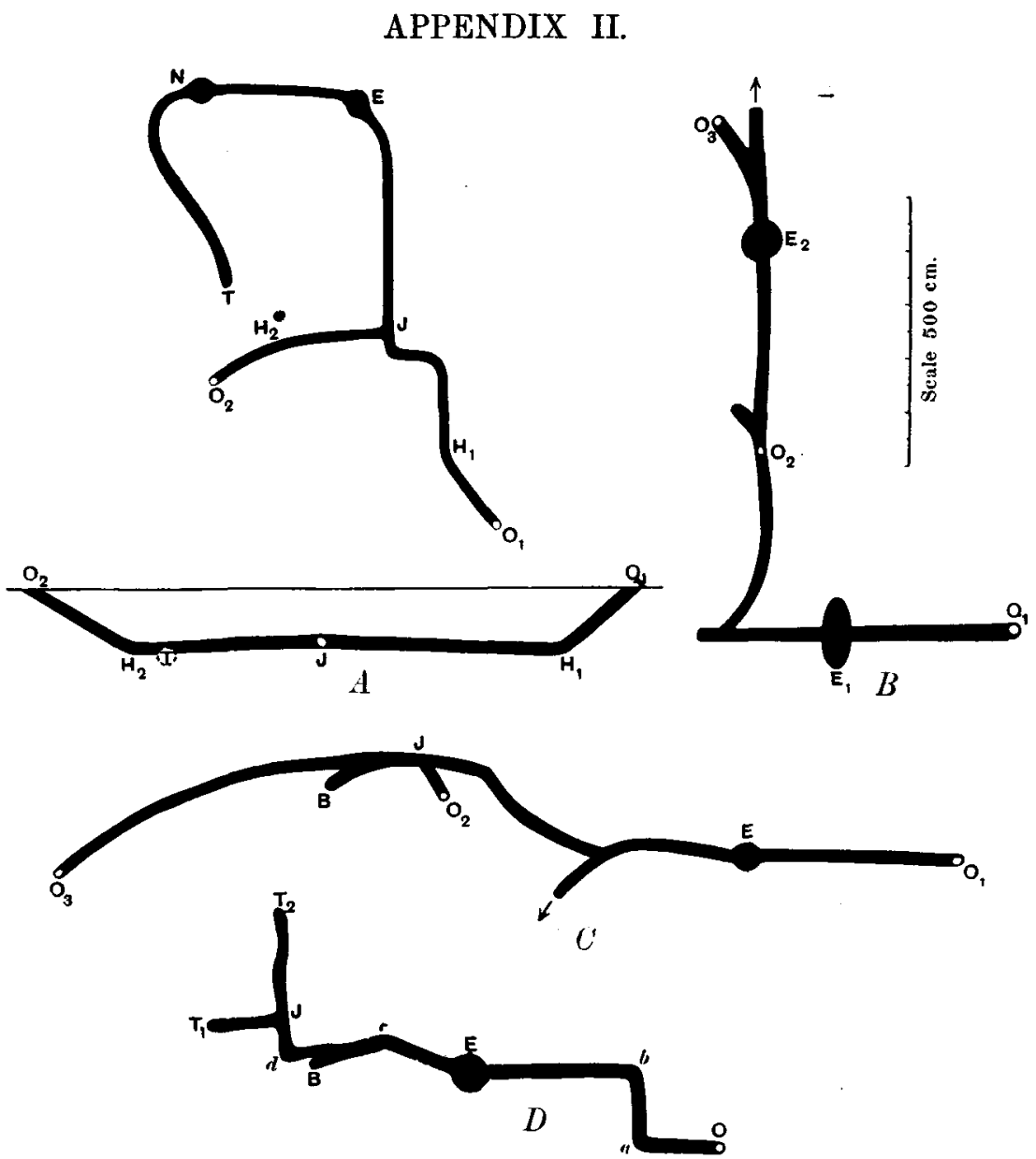

Tarbagan Burrow A. Near Manchouli. Opened Aug. 19th, 1911.

$O_{1}, O_{2}$, entrances to the burrow. $J$, junction of the tunnels from entrances $O_{1}, O_{2}$. $E$, enlargement containing faeces. $N$, enlargement containing " nest." $T$, terminus. Diameter of entrance $O_{1} 21 \mathrm{~cm}$. Diameter of entrance $O_{2} 28 \mathrm{~cm}$. $O_{1}$ to $H_{1} 195 \mathrm{~cm}$. $\mathrm{O}_{2}$ to $\mathrm{H}_{2} 239 \mathrm{~cm}$. $\mathrm{H}_{1}$ to $\mathrm{J} 452 \mathrm{~cm}$. $\mathrm{H}_{2}$ to $\mathrm{J} 355 \mathrm{~cm}$. J to $E 276 \mathrm{~cm}$. $E$ to $N 284 \mathrm{~cm}$. N $N$ to $T 479 \mathrm{~cm}$. Whole length from $O_{1}$ to $T 1633 \mathrm{~cm}$. Diameter of $E 72 \mathrm{~cm}$. Diameter of $N 58 \mathrm{~cm}$. Distance from $O_{1}$ to $O_{2} 623 \mathrm{~cm}$. Depth at $\mathrm{J} 102 \mathrm{~cm}$. Depth at $\mathrm{T} 124 \mathrm{~cm}$.

Tarbagan Burrow B. Near Manchouli. Opened Aug. 19th, 1911.

$O_{1}, O_{2}, O_{3}$, entrances to burrow. $E_{1}, E_{2}$, enlargements.

Diameter of entrance $O_{1} 23 \mathrm{~cm}$. Distance from $O_{1}$ to horizontal $304 \mathrm{~cm} . O_{1}$ to $E_{1} 308 \mathrm{~cm}$. Size of $E_{1} 140$ by $50 \mathrm{~cm}$. 
Tarbagan Burrow C. Near Manchouli. Opened Aug. 22nd, 1911.

$O_{1}, O_{2}, O_{3}$, entrances to burrow. $E$, enlargement. $J$, junction of tunnel from entrance $O_{2}$. $B$, blind end. From entrance $O_{1}$ the tunnel sloped downwards to $E$, a distance of $304 \mathrm{~cm}$.

$E$ to $J 725 \mathrm{~cm}$. $J$ to $B 177 \mathrm{~cm}$. $J$ to $O_{3} 780 \mathrm{~cm}$. Deepest part of the burrow $110 \mathrm{~cm}$. The blind end $B$ connected with the surface. From $O_{2}$ to $O_{3}$ the ground was very stony.

Tarbagan Burrow D. Near Manchouli. Opened in March 1911.

Measurements taken in Aug. 1911.

This was one of the Burrows opened by the Finn hunter in March 1911 to obtain Tarbagans for the International Plague Conference. When opened the ground was frozen and the Tarbagans were hibernating.

$O$, entrance to the burrow. $E$, enlargement. $B$, blind end. $T_{1}, T_{2}$, Tarbagans found here by the hunter.

$O$ to $a 166 \mathrm{~cm}$. $a$ to $b 142 \mathrm{~cm}$. $b$ to $c 385 \mathrm{~cm}$. $c$ to $B 142 \mathrm{~cm}$. B to $d 72 \mathrm{~cm}$. $d$ to $\mathrm{J} 72 \mathrm{~cm}$. J to $\mathrm{T}_{1} 129 \mathrm{~cm}$. $J$ to $\mathrm{T}_{2} 213 \mathrm{~cm}$.

\title{
APPENDIX III.
}

\author{
Translation of the Chinese Order prohibiting the hunting \\ of Tarbagans (April, 1911).
}
Prohibition Order regarding Tarbagan Hunting, Hsuan Tung, 3rd Moon, 20th Day.

\section{By The Hulun Taotai.}

1. Anyone found in possession of traps or other instruments for catching Tarbagans is liable to have these traps or other instruments confiscated and will not be allowed to continue to hunt.

2. Any cart found conveying Tarbagans or Tarbagan skins is liable to confiscation. The driver of the cart and the hunter will be punished.

3. Any tent intended for the use of Tarbagan hunters and any Tarbagan skins found by the Government officials are liable to be burnt and any hunter found disobeying this Order will be punished by 6 months' imprisonment.

4. No Chinese or Russian is allowed to sell Tarbagan skins. Anyone found disobeying this Order will be arrested and handed over to the proper authorities for punishment.

5. Any Chinese disobeying this Order will be tried by the local authorities. Any Russian disobeying this Order will be handed over to the Russian authorities for trial.

The above Orders are made in order to prevent a recurrence of Plague. 


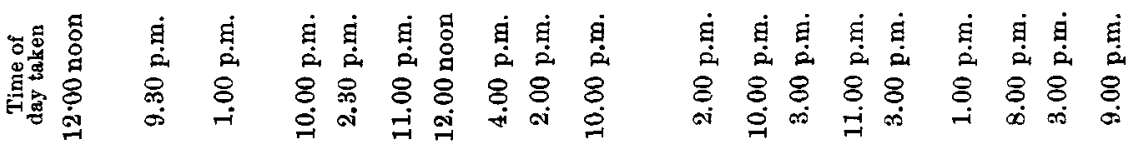

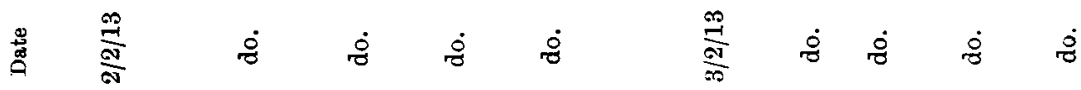

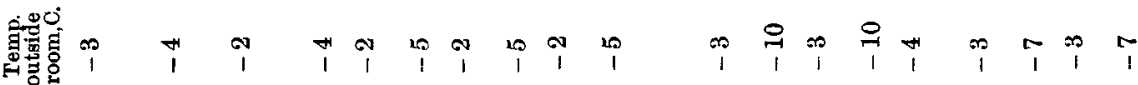

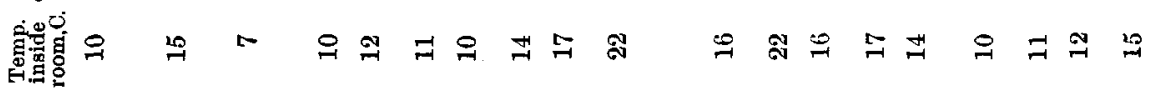

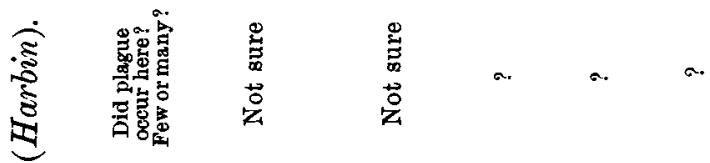

喓
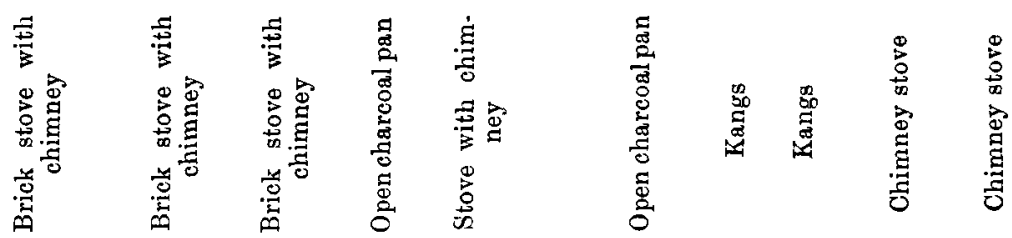

离

\begin{tabular}{|c|c|c|c|c|c|c|c|c|c|}
\hline 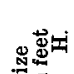 & ตี & 0. & $n$ & $\infty$ & $\sigma$ & $n$ & 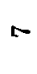 & - & $\cong$ \\
\hline 4. & 9 & $\stackrel{\mathscr{H}}{\sim}$ & 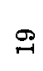 & จิ & 車 & $\stackrel{-}{\sim}$ & 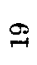 & $\stackrel{\sim}{\rightarrow}$ & $\stackrel{乛}{9}$ \\
\hline נ丶万נ口. & ๙ิ & $\stackrel{乛}{-1}$ & జ్ల & ๙ึ & $\underset{\infty}{\infty}$ & $\asymp$ & $\stackrel{\ominus}{\circ}$ & g & $\sigma_{-i}$ \\
\hline
\end{tabular}

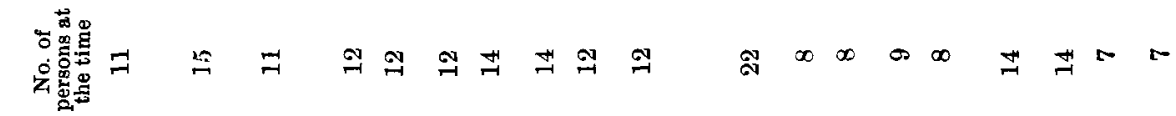

3

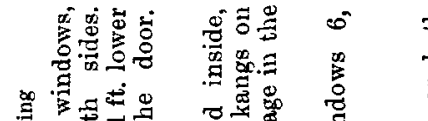

ह

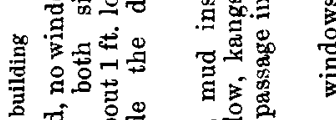

政

还

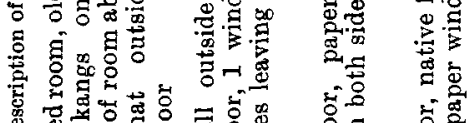

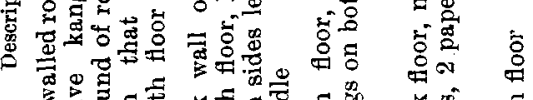

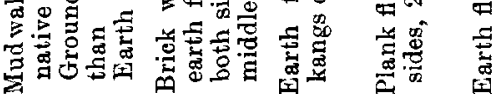

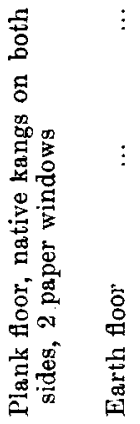

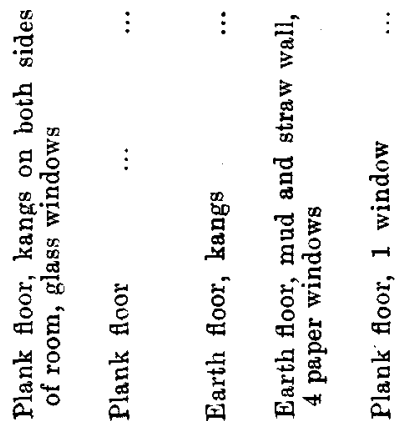

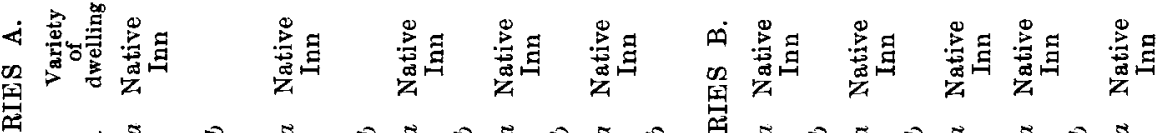

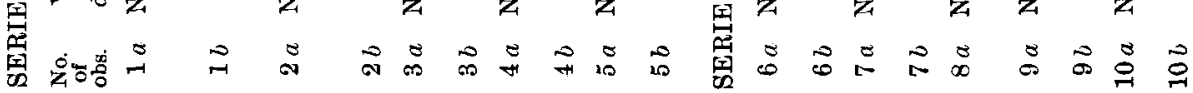




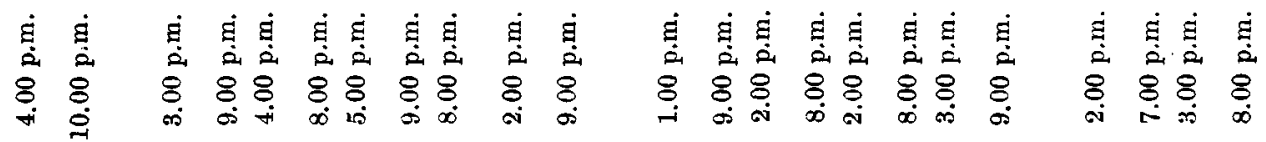

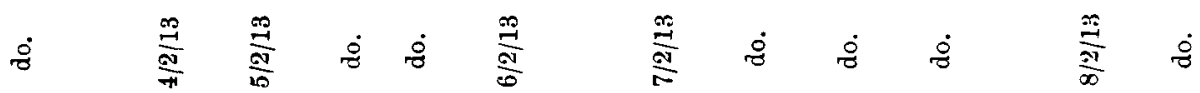

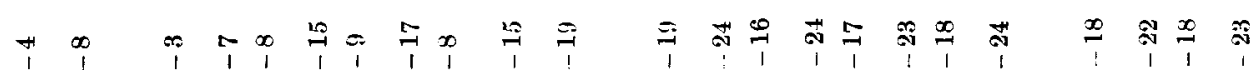

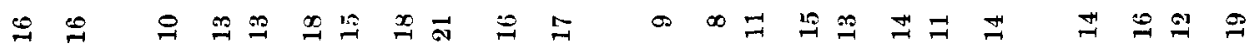

\begin{tabular}{|c|c|c|c|c|c|c|c|c|c|c|}
\hline 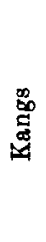 & 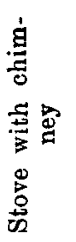 & 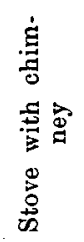 & 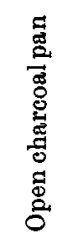 & 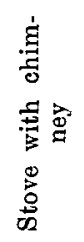 & 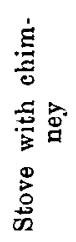 & 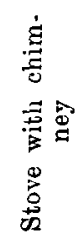 & 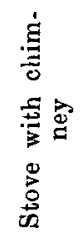 & 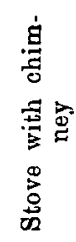 & 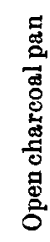 & 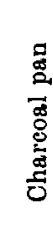 \\
\hline$\infty$ & $\infty$ & $\theta$ & $\approx$ & $\infty$ & $\infty$ & $\sim$ & $r$ & $\infty$ & $\infty$ & $n$ \\
\hline 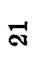 & $\stackrel{\rightarrow}{-1}$ & $\stackrel{\Im}{\Im}$ & I & $\overrightarrow{\mathrm{N}}$ & $r$ & $\stackrel{2}{=}$ & $\overline{\mathrm{N}}$ & $\stackrel{\Omega}{2}$ & $\stackrel{\theta}{=}$ & 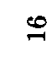 \\
\hline & $\stackrel{2}{2}$ & $\vec{\pi}$ & $r$ & $\overrightarrow{\text { ส }}$ & $\stackrel{9}{\prime}$ & జ̊ & 9 & $\mathscr{B}$ & $\stackrel{\infty}{\infty}$ & 9 \\
\hline
\end{tabular}

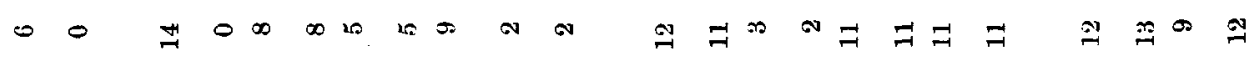

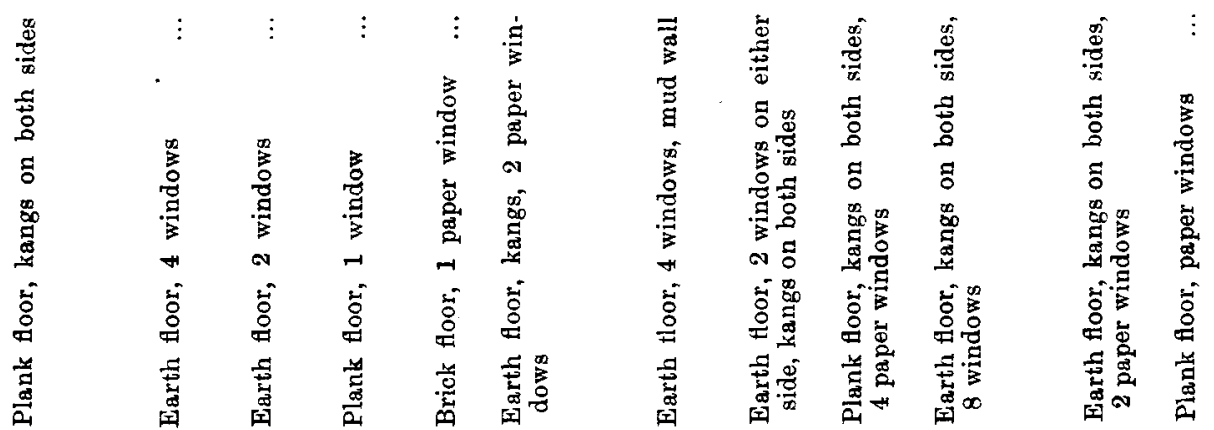

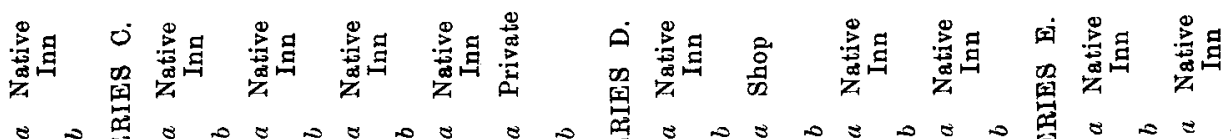

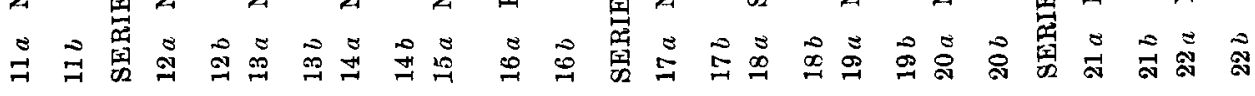
Journ, of Hyg. xrII 


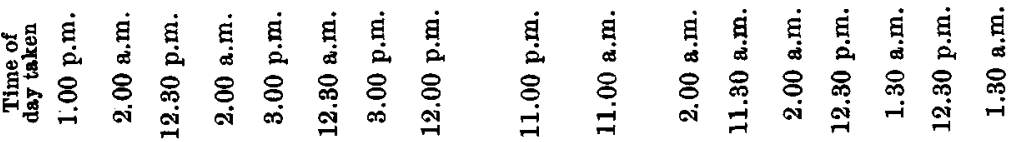

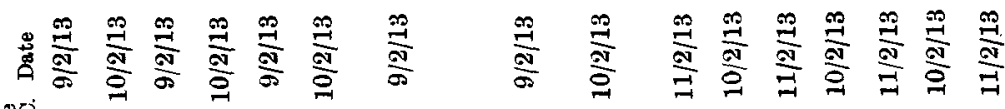

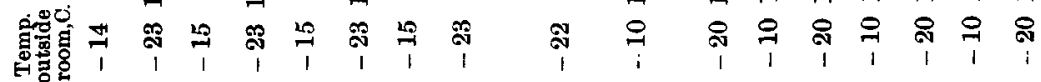

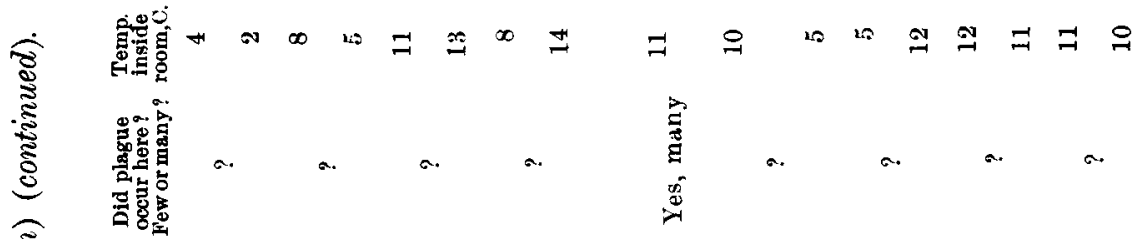

记

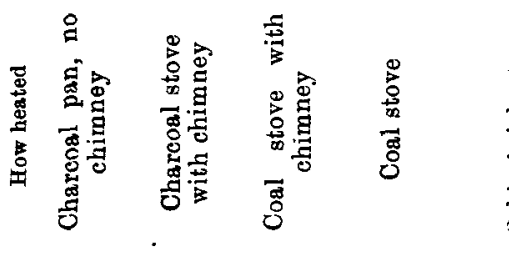

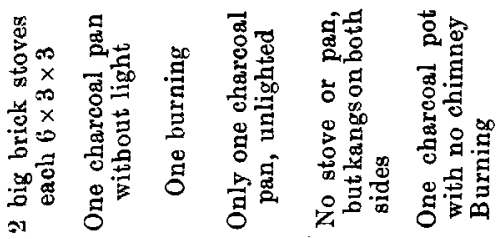

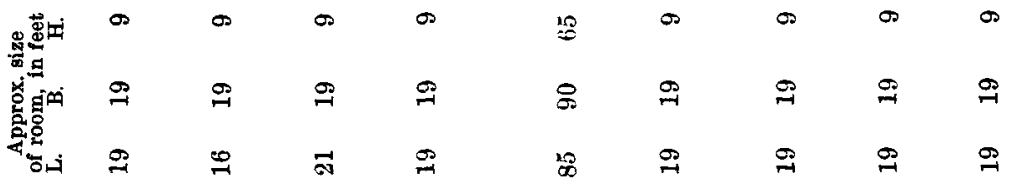

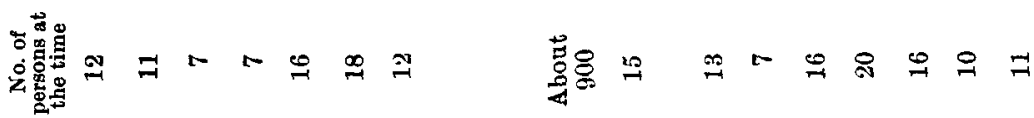

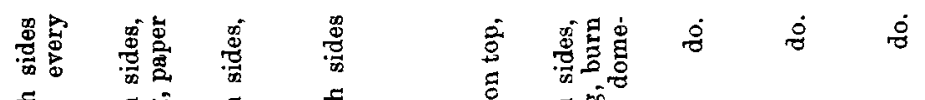

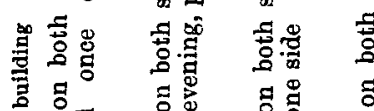

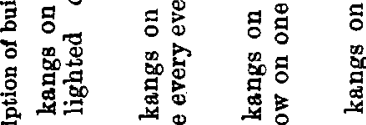

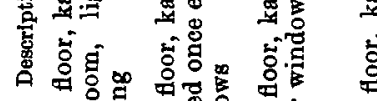

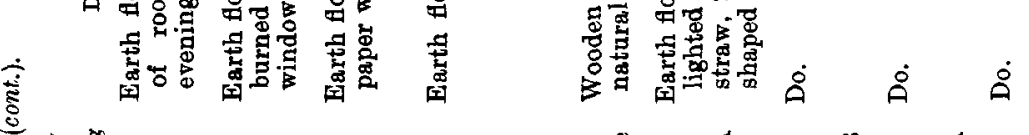

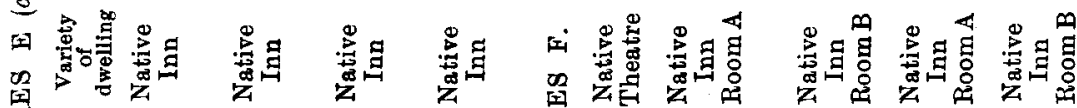
窟

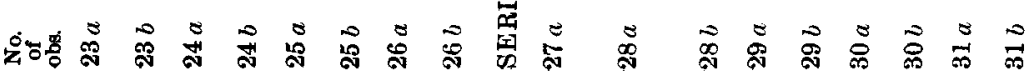




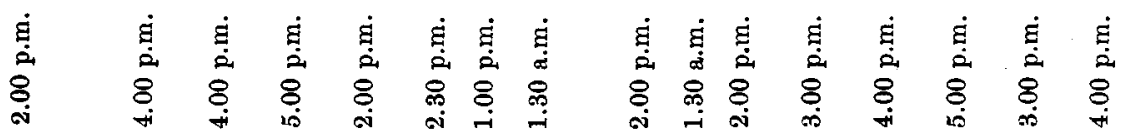

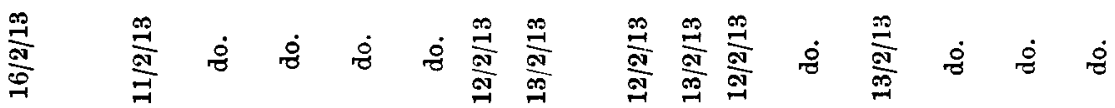

i. $\rightarrow$ i $i$ i

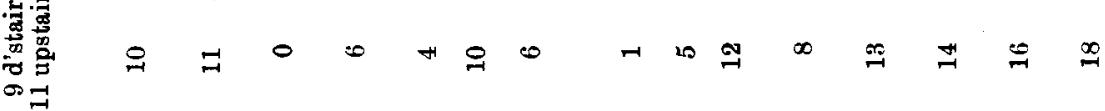

总

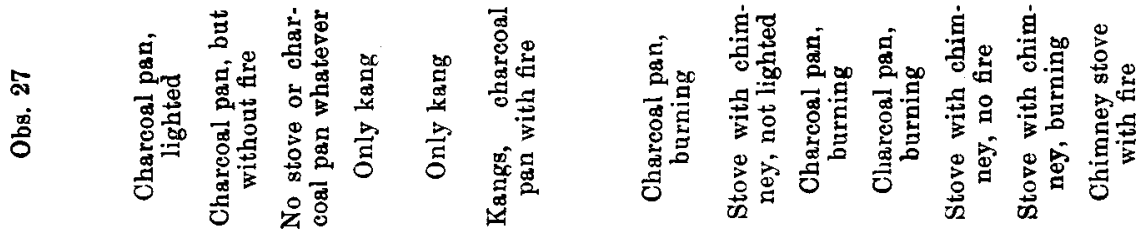

$: 8$

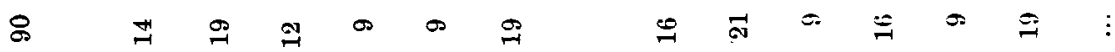

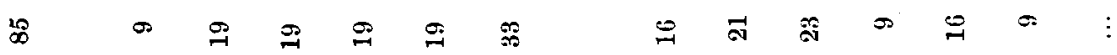

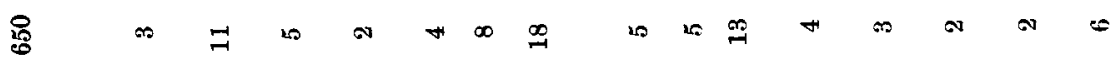

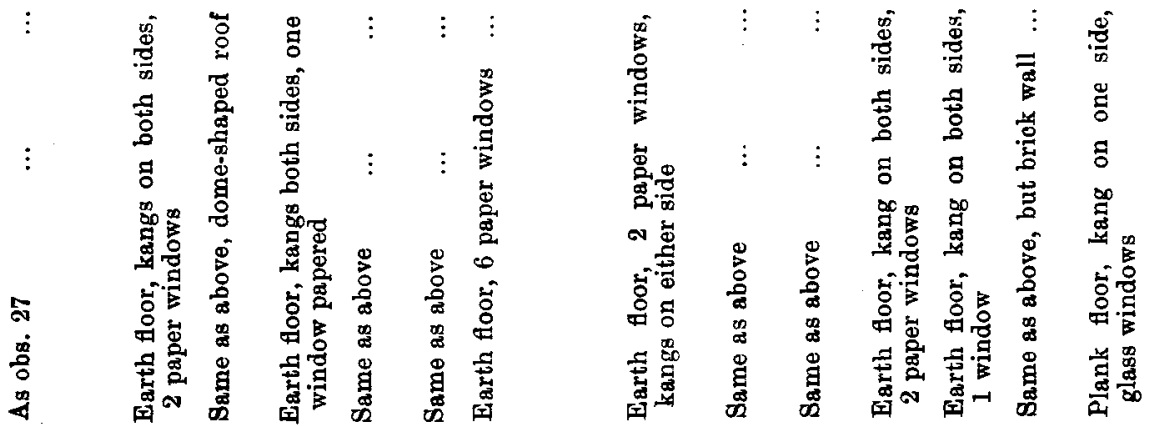

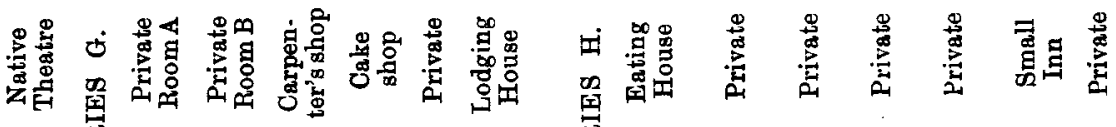

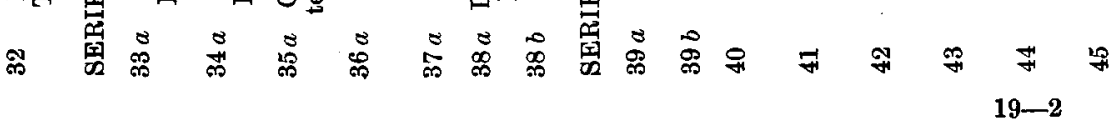


Plague in Manchuria

288

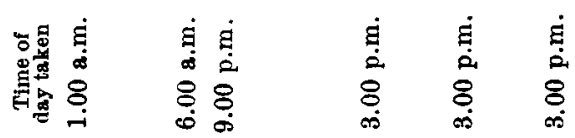

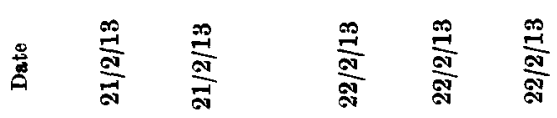

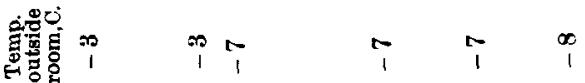

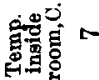

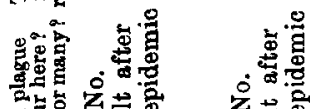

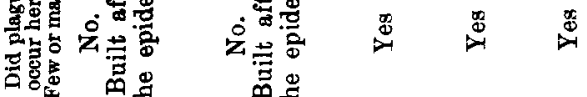

స్ర

$\approx$

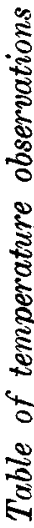

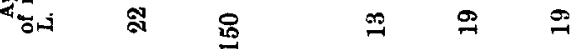

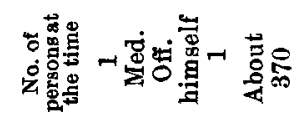

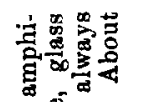

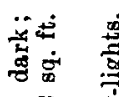

远

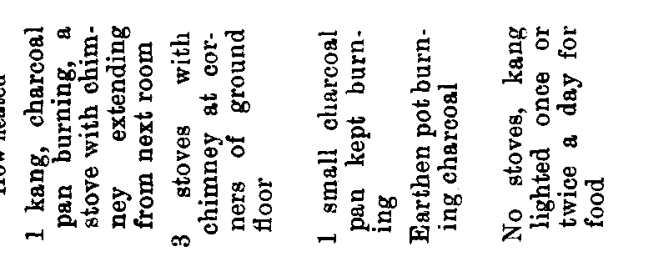

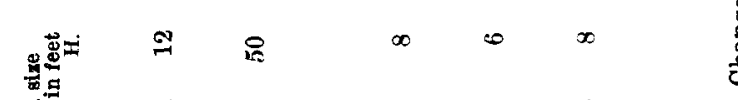

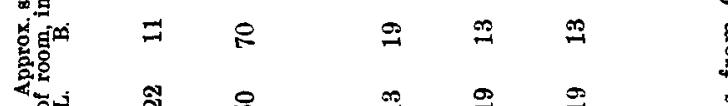

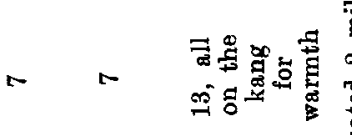

$\infty$

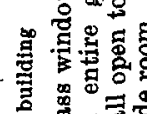

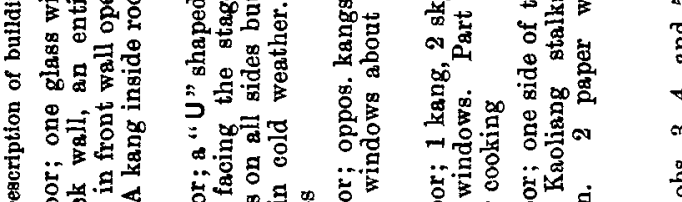

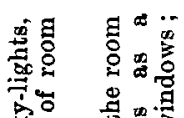

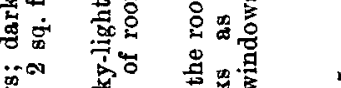

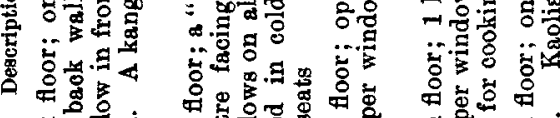

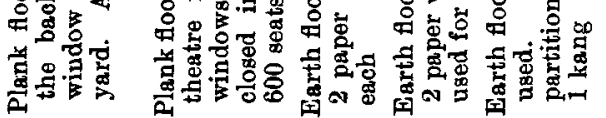

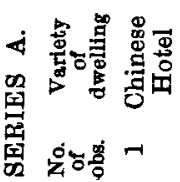

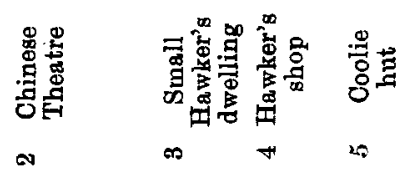

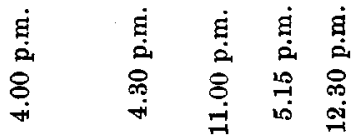

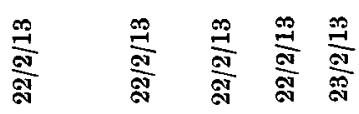

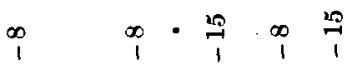

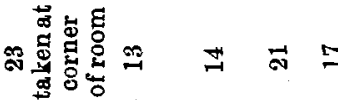

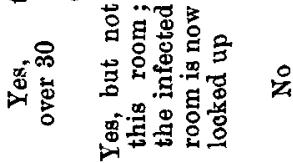

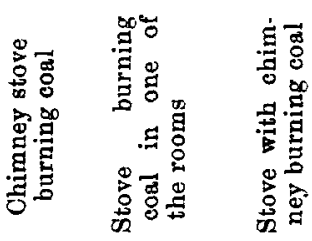

$=\infty \quad \infty$

요

ถึก คิ

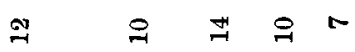

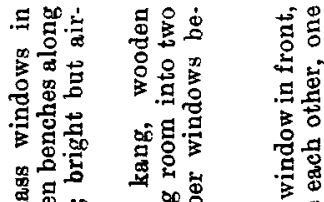

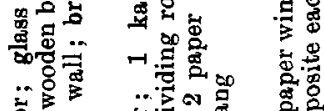

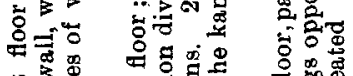

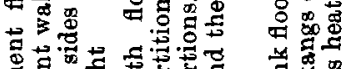

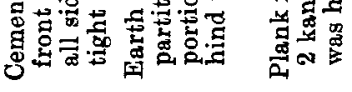

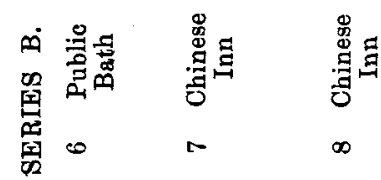




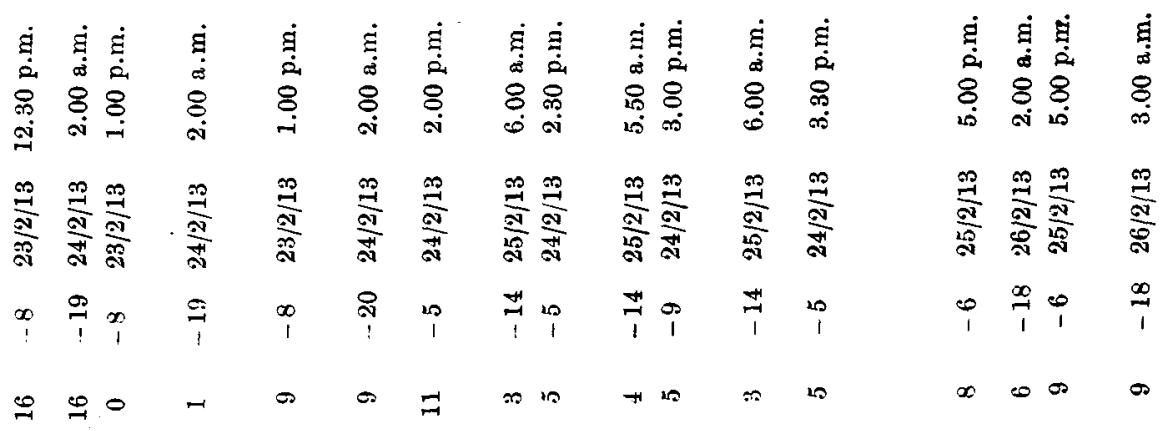

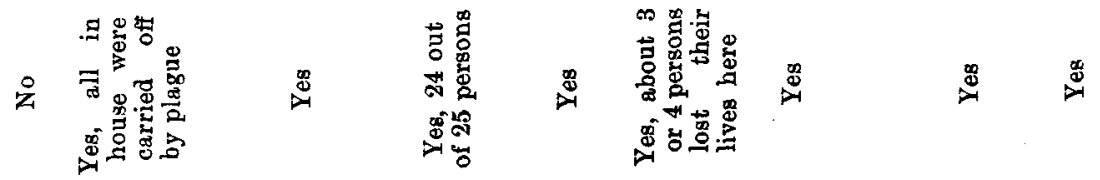

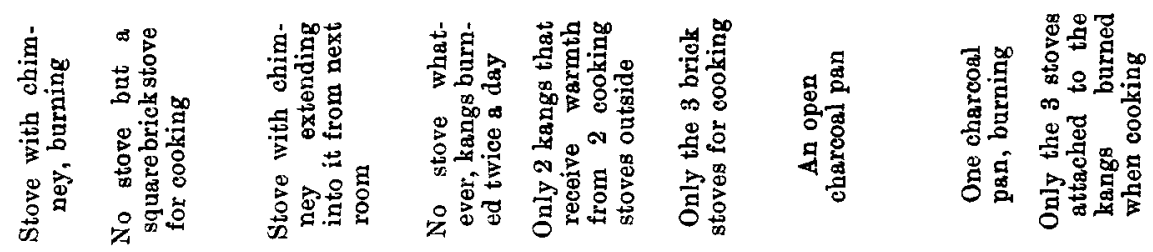

\begin{tabular}{|c|c|c|c|c|c|c|c|}
\hline 요 & $\infty$ & $\infty$ & $\stackrel{ }{-1}$ & $\sigma$ & $\Rightarrow$ & $\infty$ & 요 \\
\hline สี & $\vec{a}$ & $\stackrel{20}{-1}$ & $\underset{-}{ \pm}$ & $\stackrel{\infty}{-1}$ & 斿 & $\approx$ & శ్ \\
\hline o & $\simeq$ & 요 & $\bar{\infty}$ & $\stackrel{9}{\mathscr{2}}$ & జ్ & శิ & $\not \vec{~}$ \\
\hline
\end{tabular}

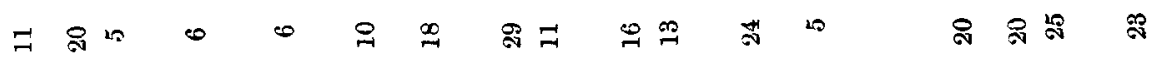

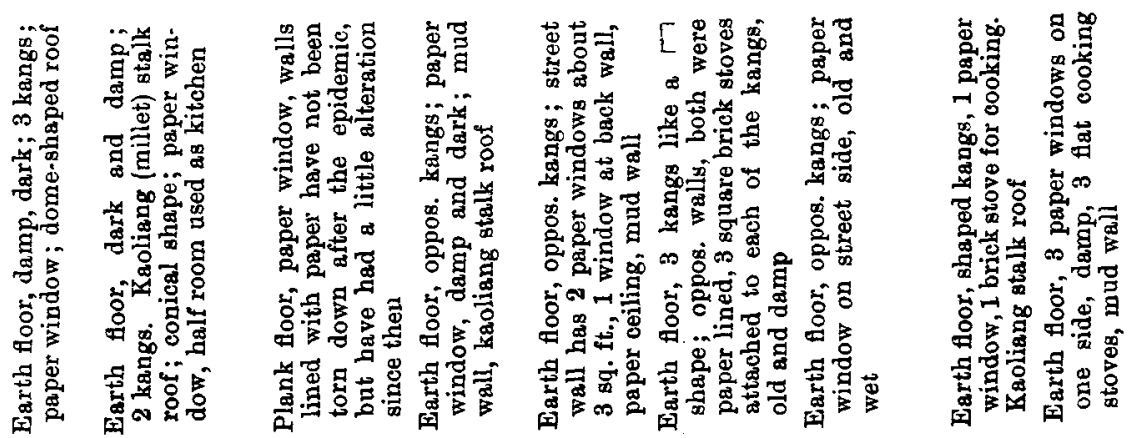

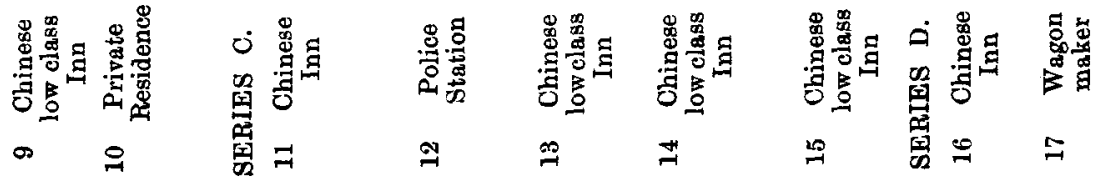




\section{APPENDIX IV. \\ Temperature Observations in Fuchiatien (Harbin) and in Changchun.}

In reply to a request made by Dr Oscar Teague (American delegate to the Mukden Plague Conference) for particulars of temperatures inside and outside houses of towns where the epidemic of 1910-11 had been most severe, e.g. Fuchiatien, Changchun, the observations comprising this Appendix were made under the personal supervision of Dr T. N. Tang, Assistant Medical Officer. The following is a summary of the recorded on pp. 284-289 data:

\section{Re Observations in Fuchiatien.}

1. The native divellings are heated by :

(a) brick stoves after the Russian style (very few);

(b) iron stoves in which coal is usually burnt;

(c) $K^{\natural}$ angs, i.e. large rectangular mud and brick structures 2 feet above the ground on which the people sit and rest, heated usually by millet stalk ;

(d) open charcoal pans without chimneys.

2. The windows consist usually of a wooden framework pasted with thin white paper, thus letting in very little light.

3. Besides the doors and the cracks in the windows, walls, and roofs, there is seldom any ventilation inside the dwellings.

4. The following are some of the more interesting observations:

(a) Period of observation, February 2nd to 13th, 1913.

(b) Number of dwellings examined 44.

(c) Number of observations taken 75 .

(d) Highest temperature recorded $\begin{cases}\text { outside } & -2^{\circ} \mathrm{C} \text {. } \\ \text { inside } & 22^{\circ} \mathrm{C} \text {. }\end{cases}$

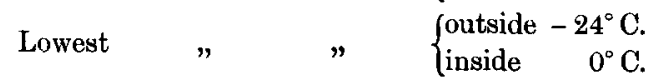

(e) Average $\quad, \quad\left\{\begin{array}{l}\text { outside }-11 \cdot 5^{\circ} \mathrm{C} \text {. } \\ \text { inside } 11 \cdot 7^{\circ} \mathrm{C} \text {. }\end{array}\right.$

\section{Re Observations in Changchun.}

(a) Period of observation, February 21st to 26th, 1913.

(b) Number of dwellings examined 17.

(c) Number of observations taken 28.

(d) Highest temperature recorded $\begin{cases}\text { outside } & -3^{\circ} \mathrm{C} \text {. } \\ \text { inside } & 23^{\circ} \mathrm{C} .\end{cases}$ Lowest $\quad$ outside $-20^{\circ} \mathrm{C}$. $\left\{\begin{array}{l}\text { outside }-20^{\circ} \mathrm{C} \text {. } \\ \text { inside }-3^{\circ} \mathrm{C} \text {. }\end{array}\right.$

(e) Average $\quad, \quad\left\{\begin{array}{lr}\text { outside } & -10 \cdot 2^{\circ} \mathrm{C} . \\ \text { inside } & 8^{\circ} \mathrm{C} .\end{array}\right.$ 


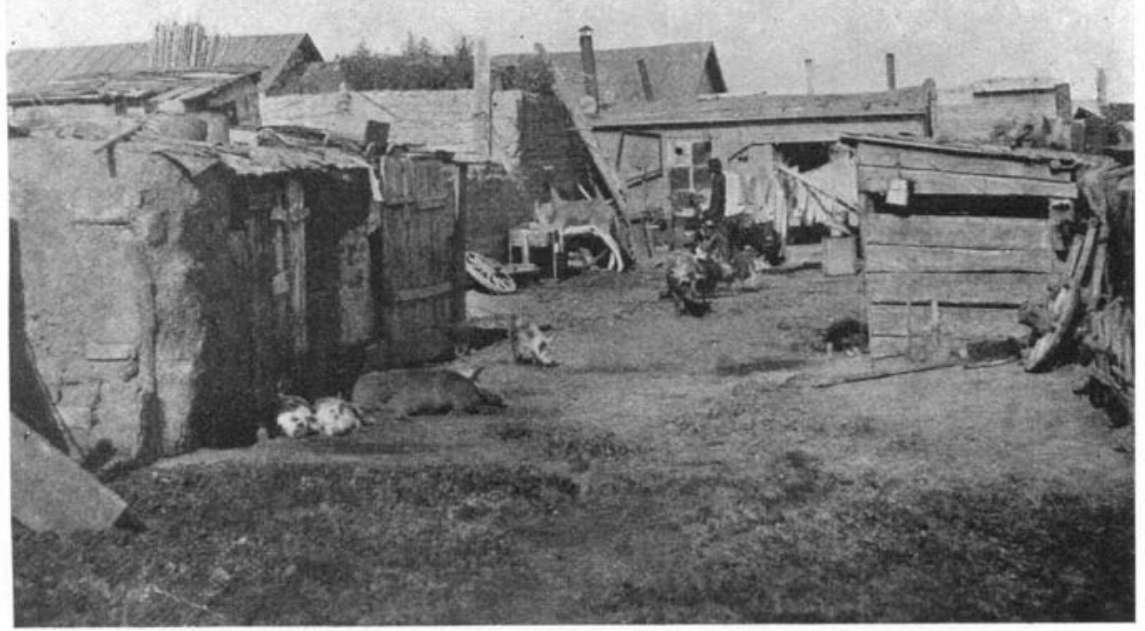

Fig. 1. Some of the inns at Manchouli. The structure seen on the right is the entrance to one of the underground type.

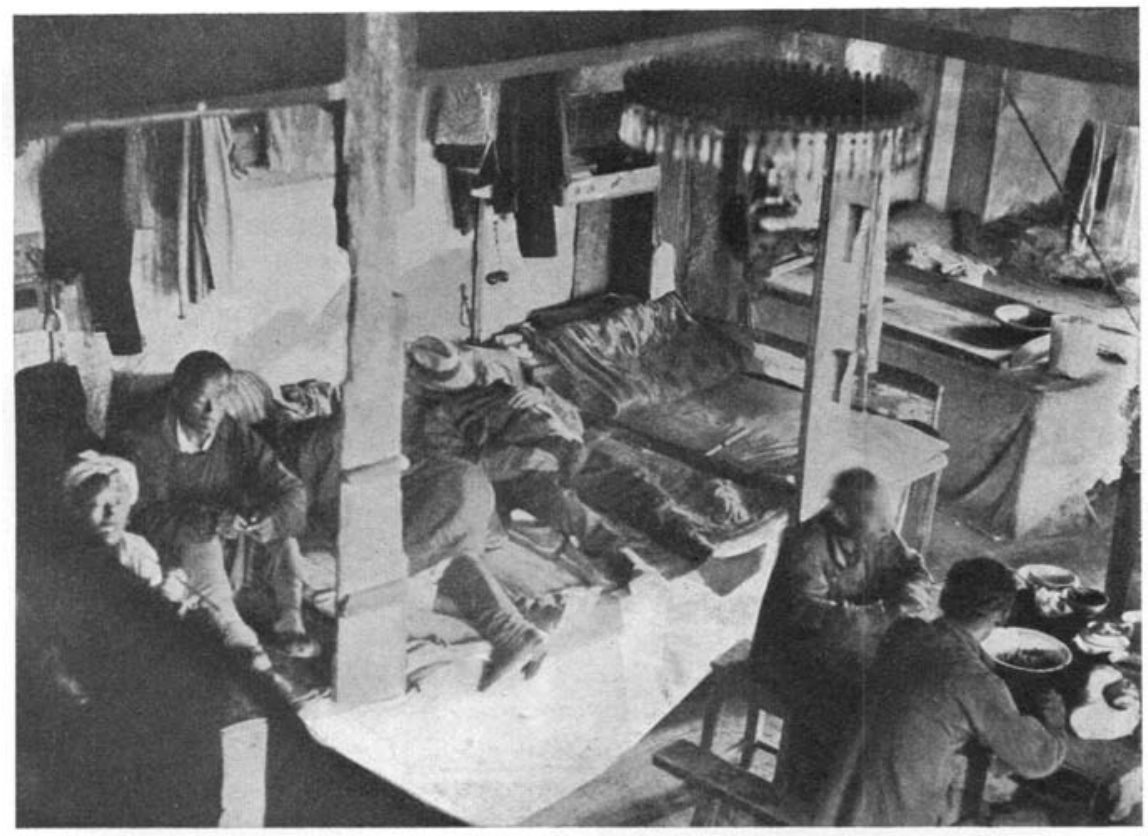

Fig. 2. Interior of an underground inn at Manchouli showing lower tier of berths. To take this photograph, it was necessary to lie at full length on one of the upper berths. 


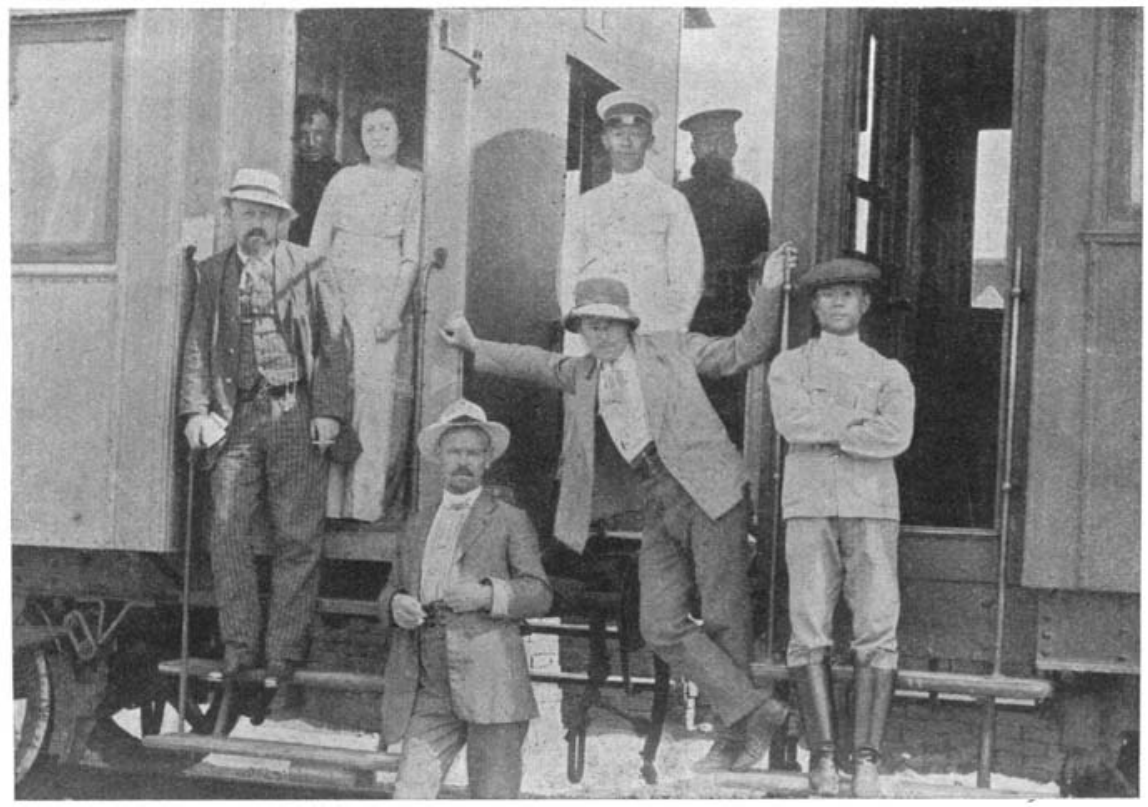

Fig. 3. The Chinese and Russian Expeditions. Borsja (Siberia), July 22nd-29th, 1911. Two of the railway cars used by us are shown in the photograph.

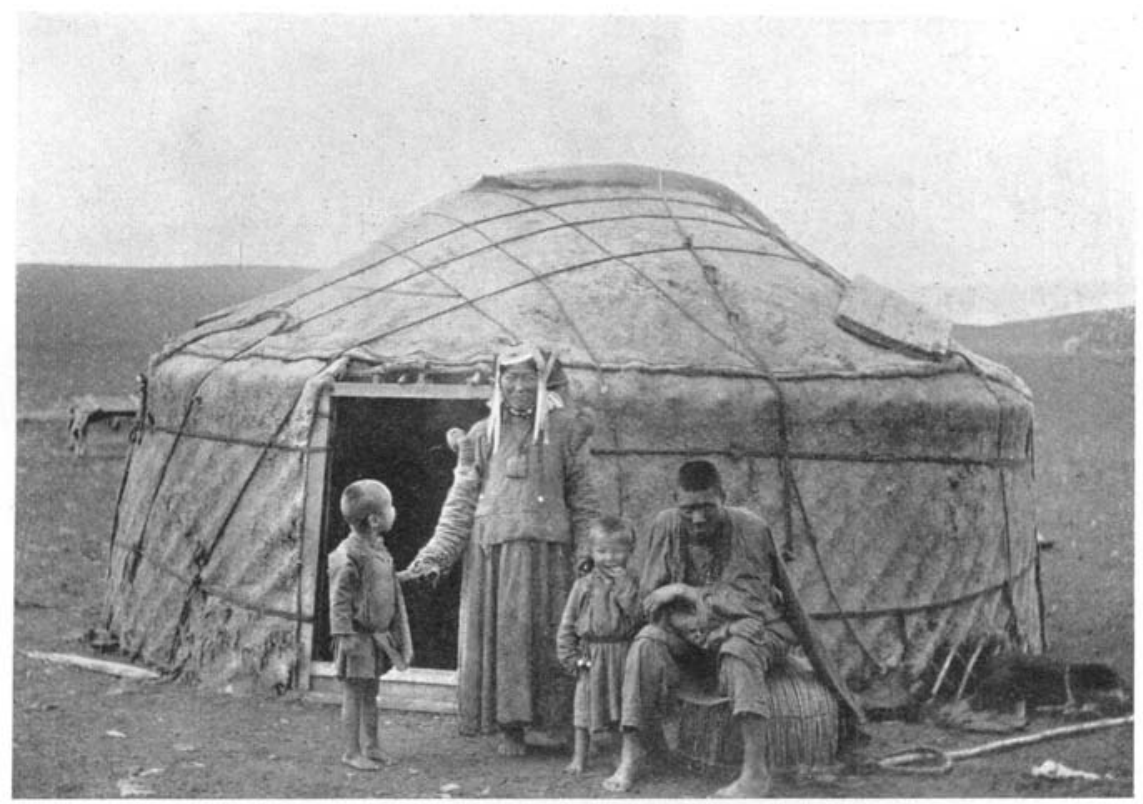

Fig. 4. A Mongol family and hut. Charbada. 


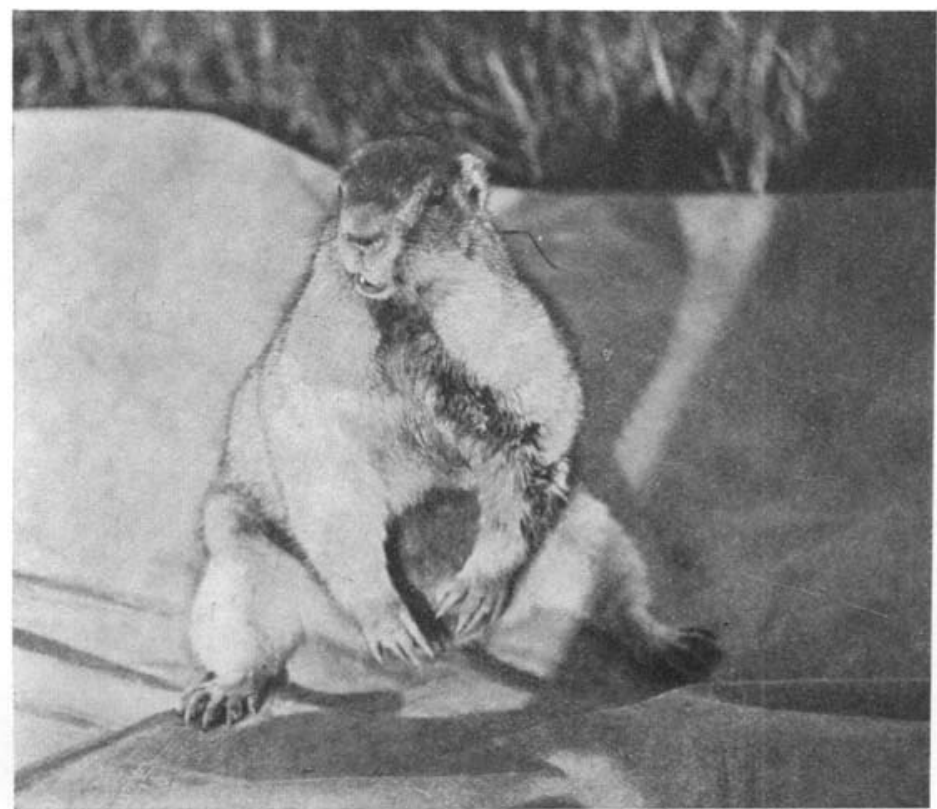

Fig. 5. The Tarbagan. The long claws are well seen.

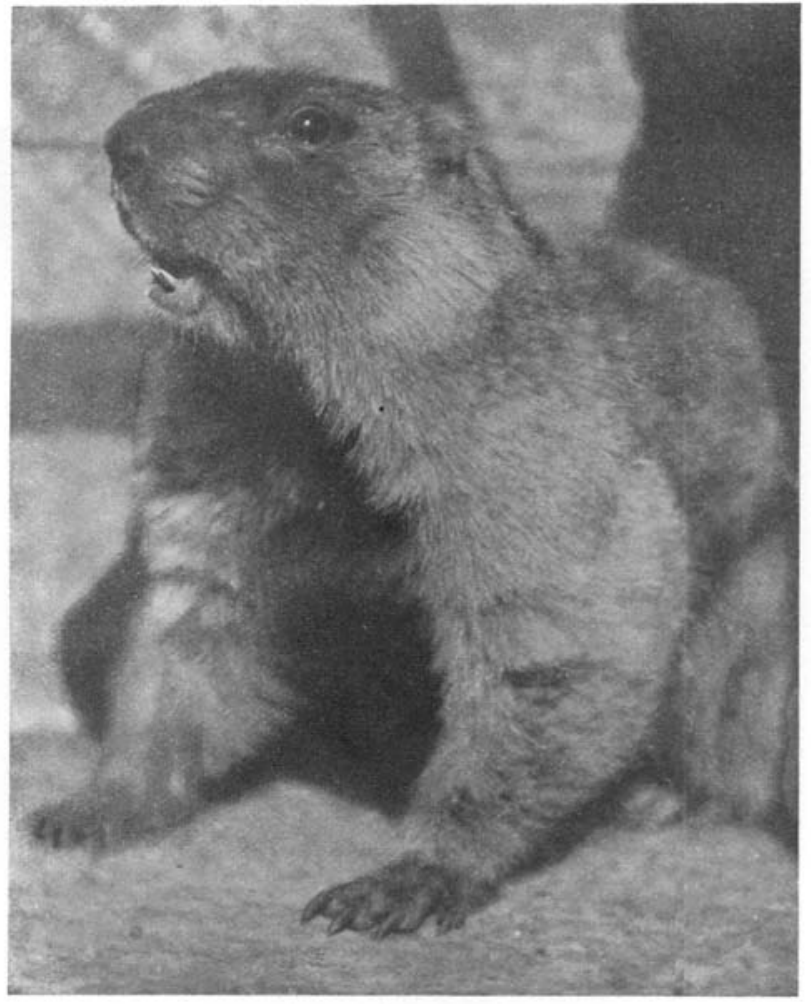

Fig. 6. The Tarbagan. Note the small ears and sharp lower incisors. 


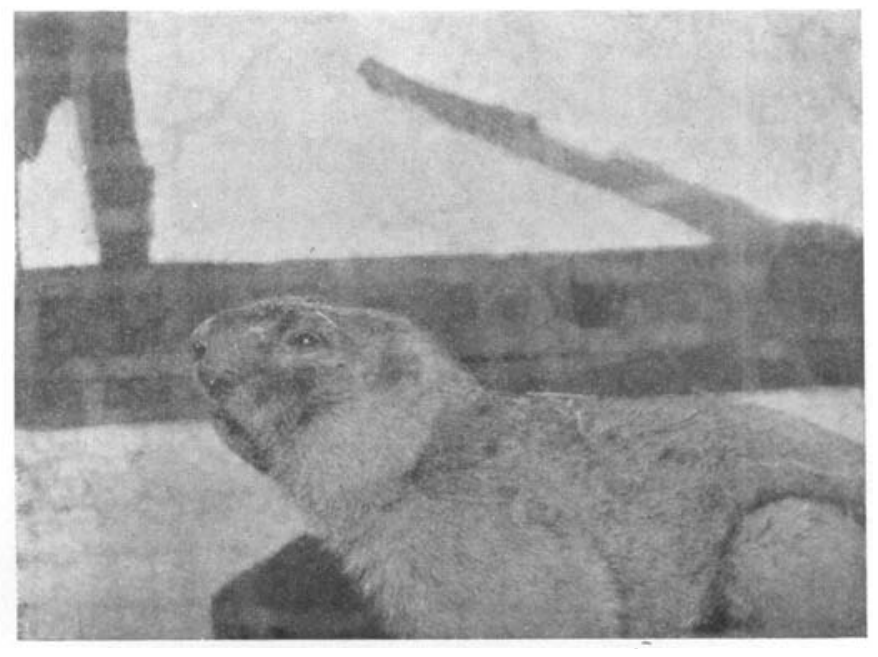

Fig. 7. The Tarbagan. Side view. Note the fierce appearance.

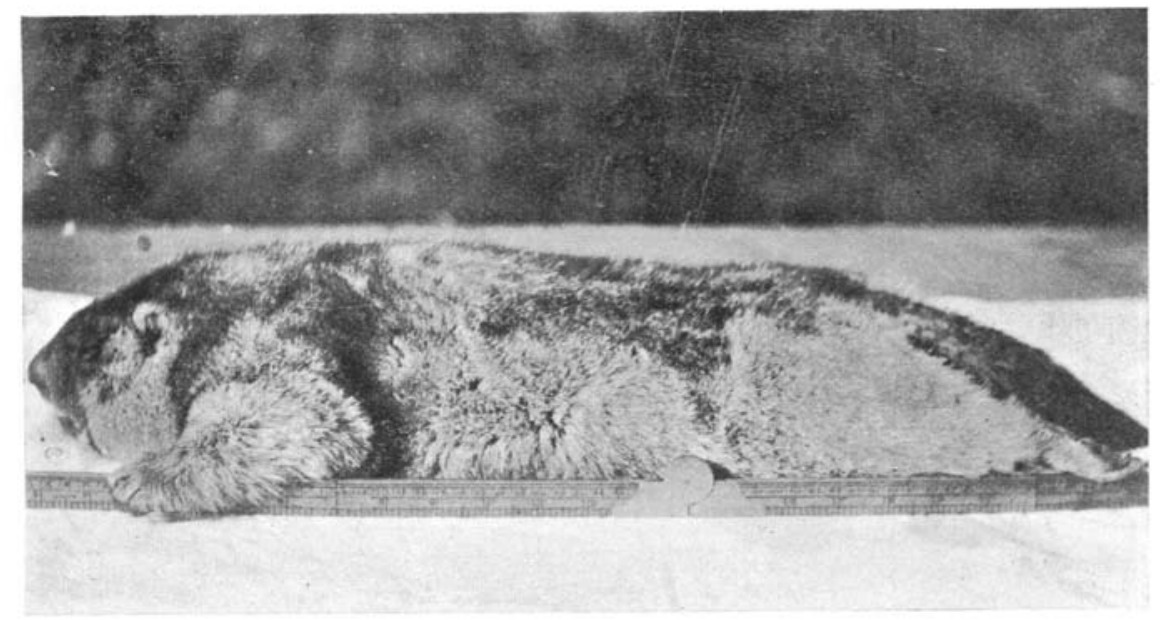

Fig. 8. A dead Tarbagan showing measurements.

Tip of nose to tip of tail $=65 \mathrm{~cm} .=25 \frac{1}{2}$ ins.

WV ", base, , $=42 \mathrm{~cm} .=16 \frac{1}{2}$ ins. 


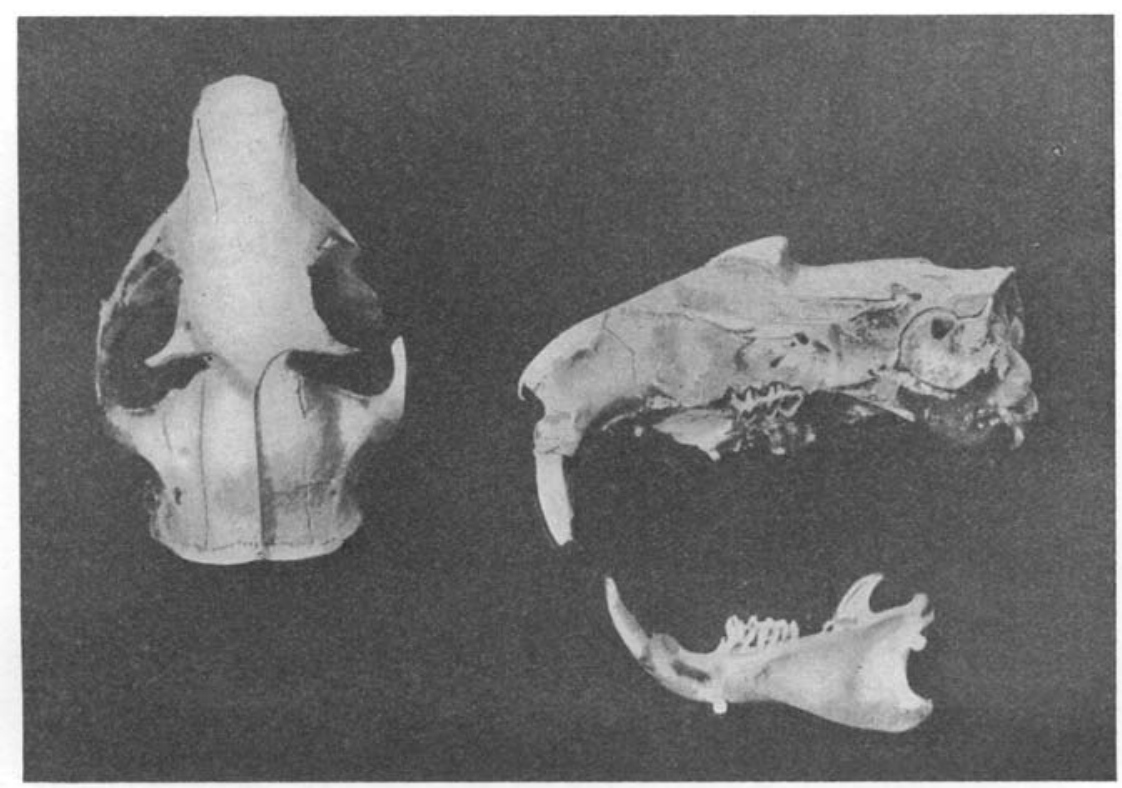

Fig. 9. Skull of Tarbagan as seen from above and laterally.

Fig. 10. The Tarbagan regions. Arabulak (Siberia). Note the mounds or "bootans" against the skyline. 
JOURNAL OF HYGIENE, VOL. XIII. NO. 3

PLATE XI

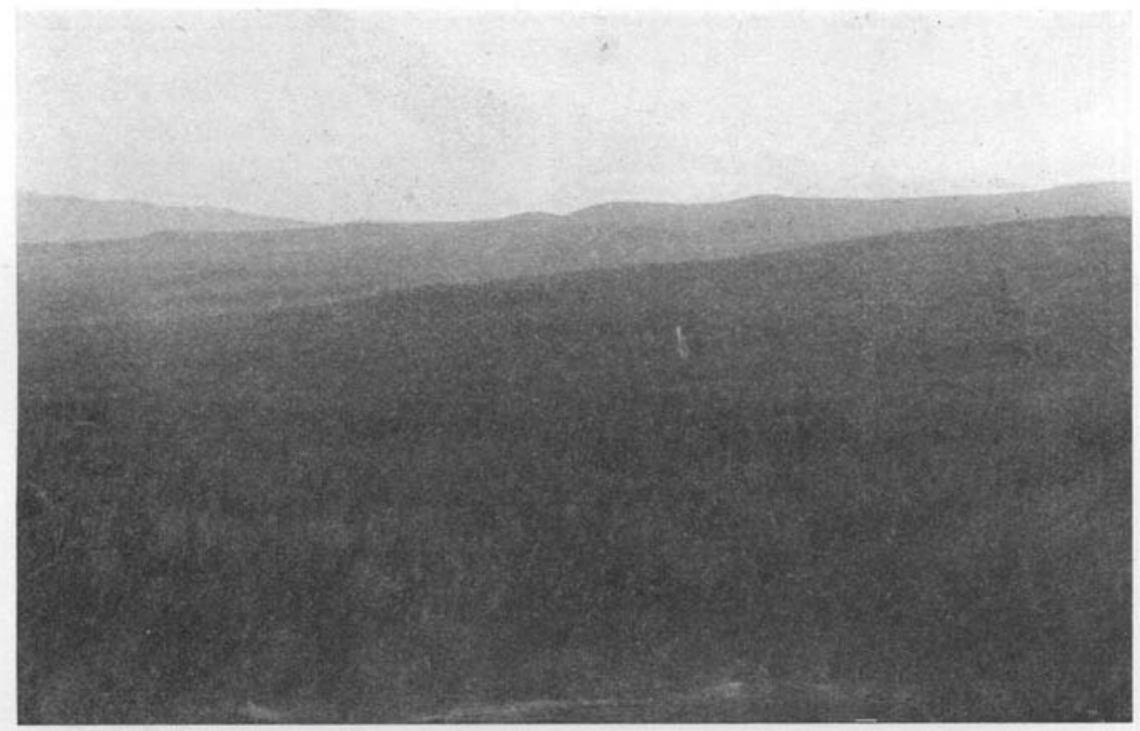

Fig. 11. The Tarbagan regions near Manchouli. Note the large mounds (against skyline) and the smaller ones in front.

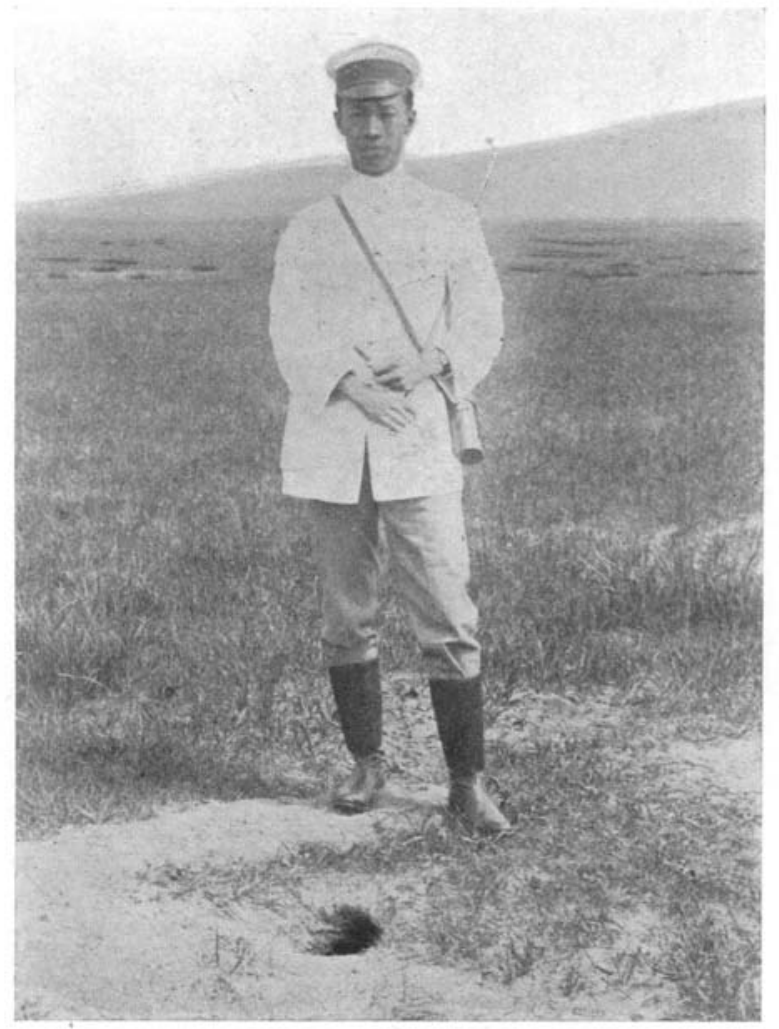

Fig. 12. Entrance to a newly made Tarbagan burrow. Tschintansk (Siberia). Note the absence of grass around the burrow. The ground was level and sandy. 


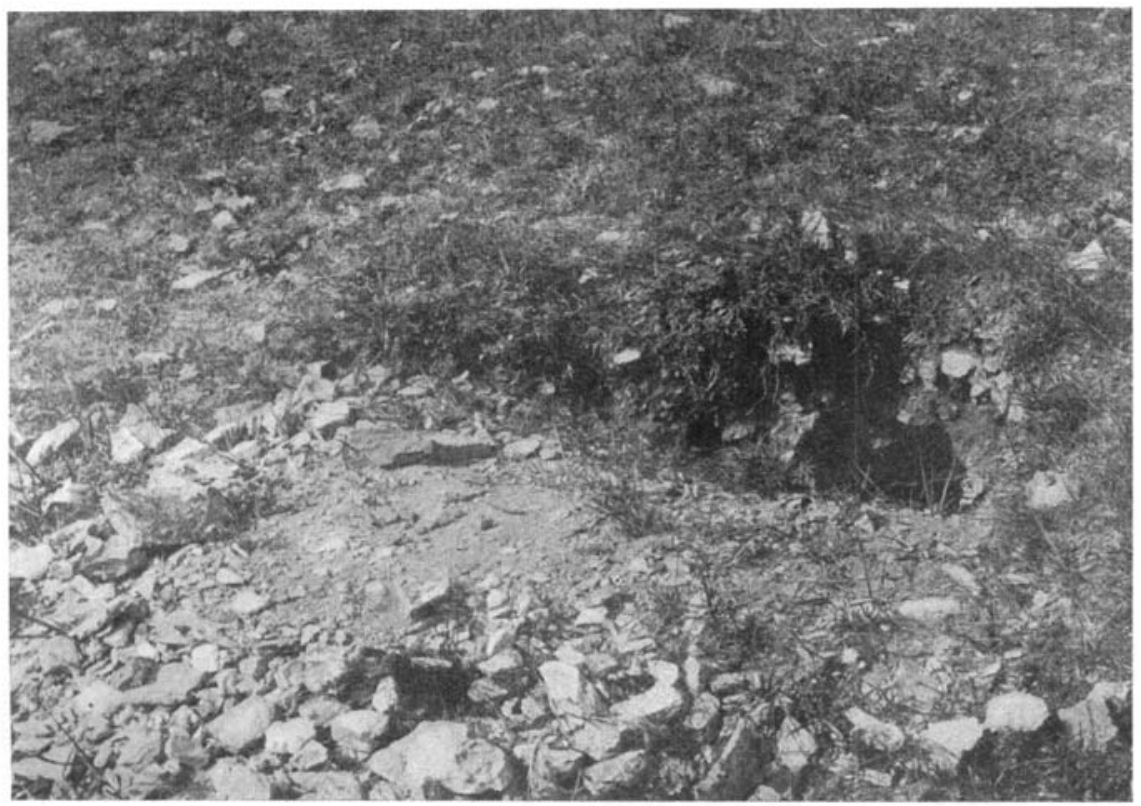

Fig. 13. Entrance to a Tarbagan burrow situated on the slope of the hill shown on Fig. 10. Arabulak. Note rocky nature of ground and faeces on the bare space to the left of burrow.

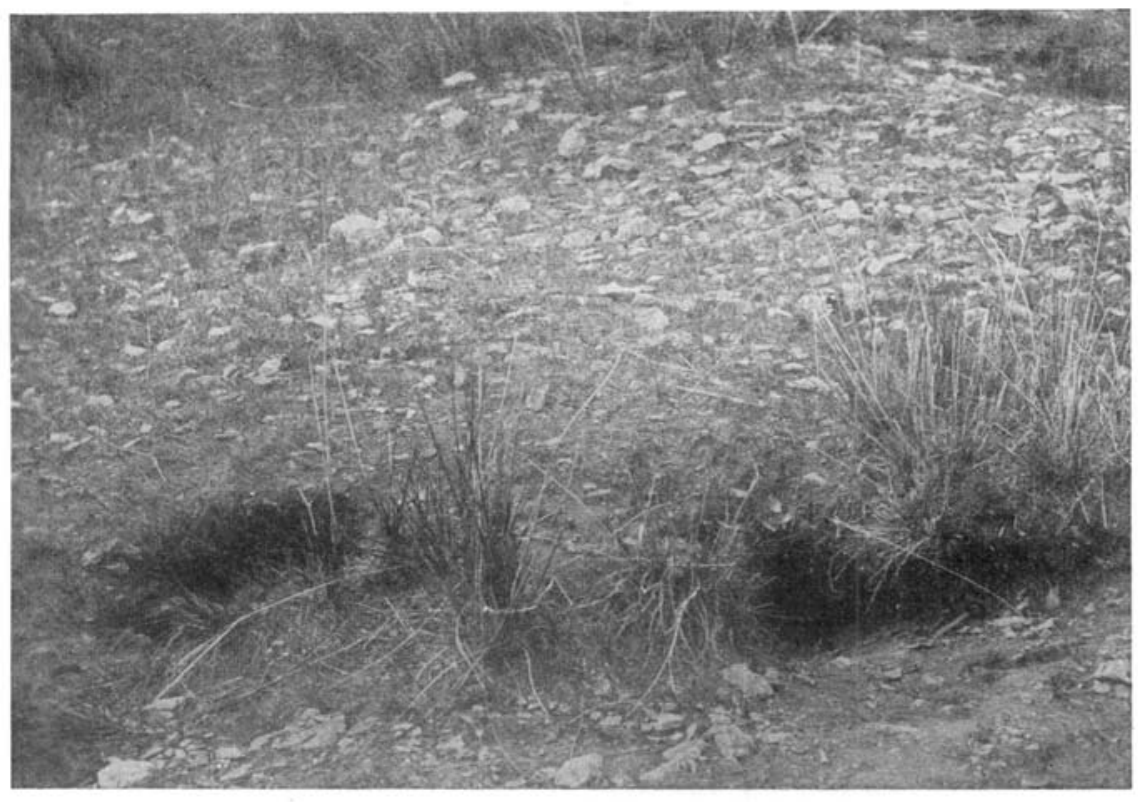

Fig. 14. Two entrances to an "Earth." Arabulak. Note the long grass on part overhanging the burrows. 


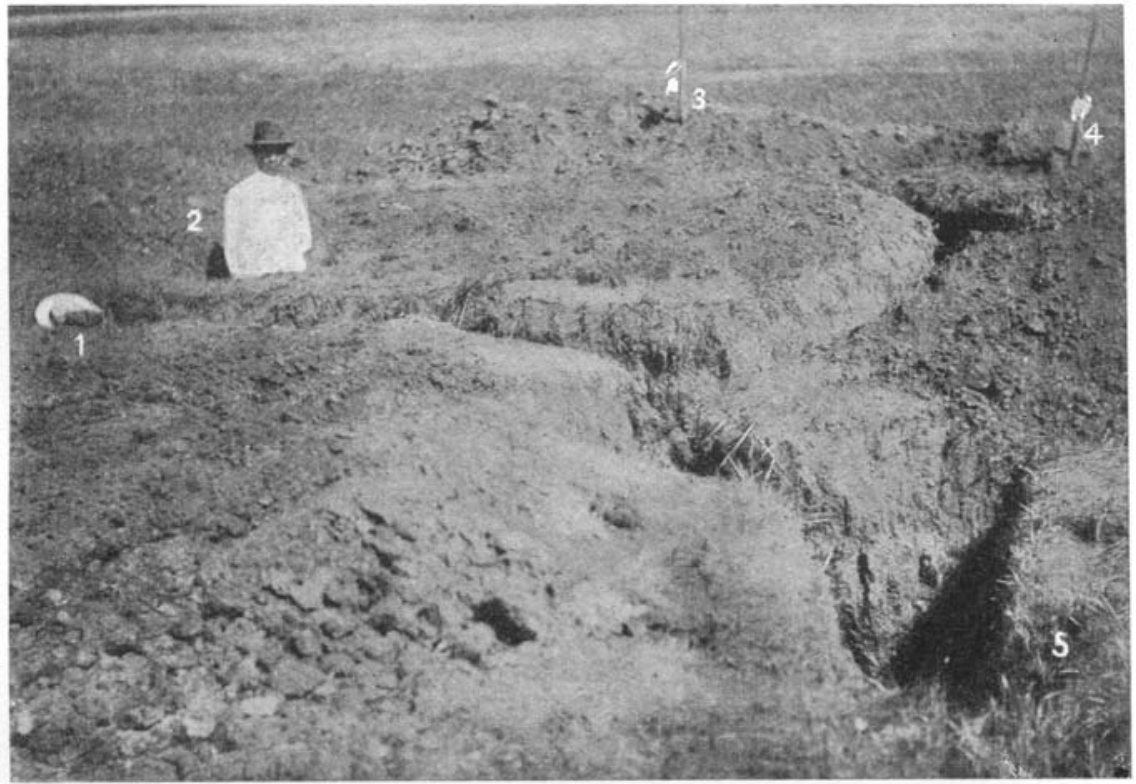

Fig. 15. Tarbagan burrow opened. No. A. Aug. 19th, 1911. Near Manchouli: In this burrow some old Tarbagan skeletons were found.

1 The hat indicates entrance 2. 2 indicates blind terminus. 3 indicates nest. 4 indicates enlarged space containing faecal matter. 5 sloping entrance 1.

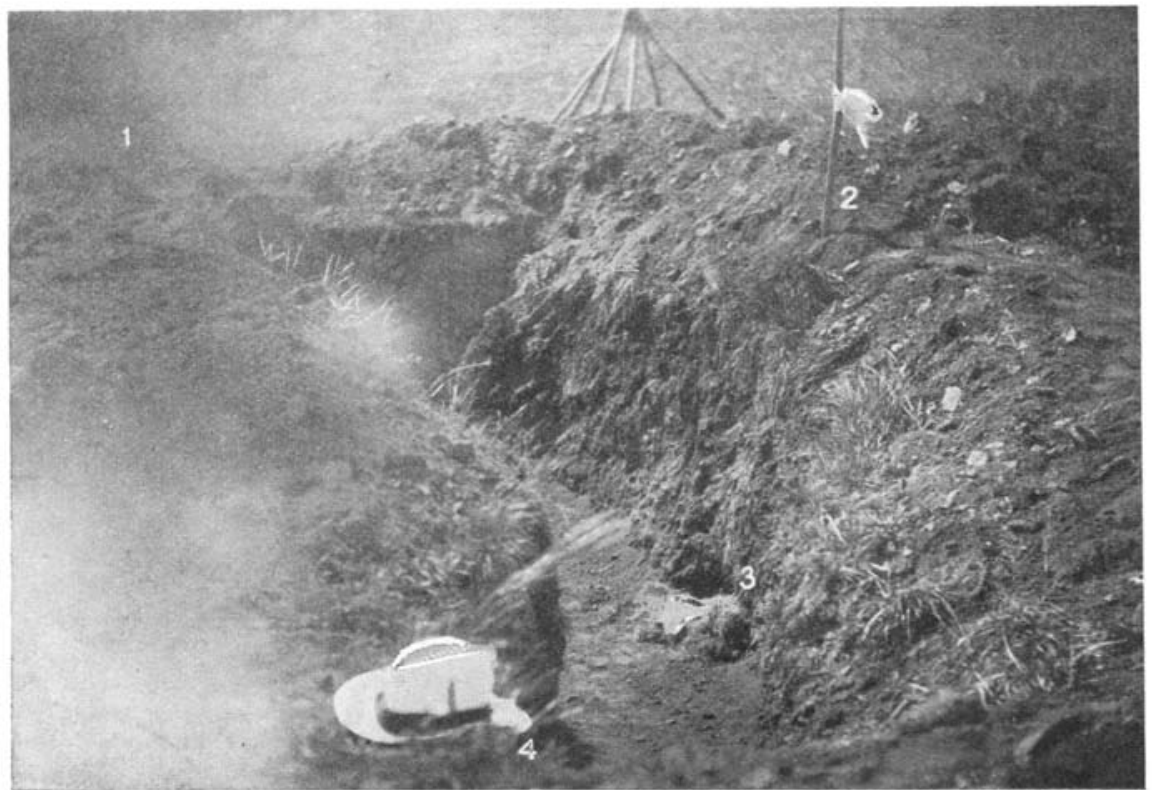

Fig. 16. Tarbagan burrow opened. No. B. Aug. 19th, 1911. Near Manchonli.

1 blind end. 2 indicates burrow going upwards. 3 enlarged space in which lies the nest, indicated by handkerchief. 4 the hat indicates sloping entrance. 


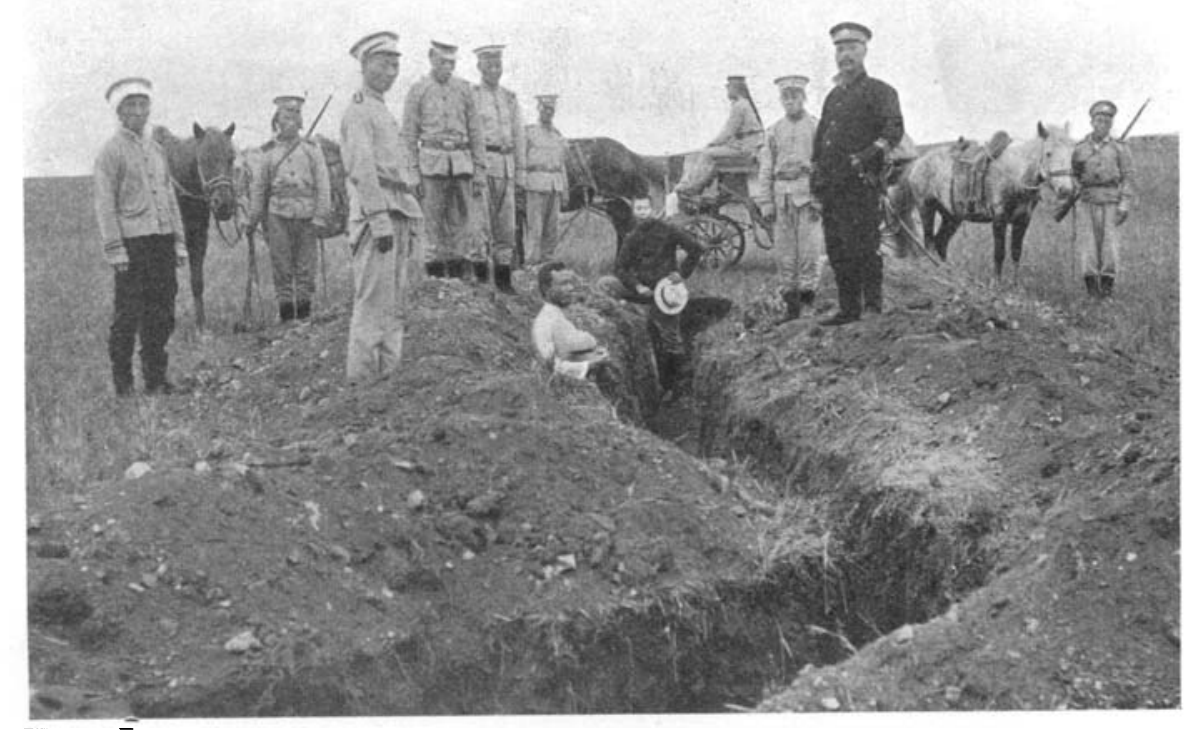

Fig. 17. Tarbagan burrow No. B traced further. Aug. 21st, 1911. Note its great depth.

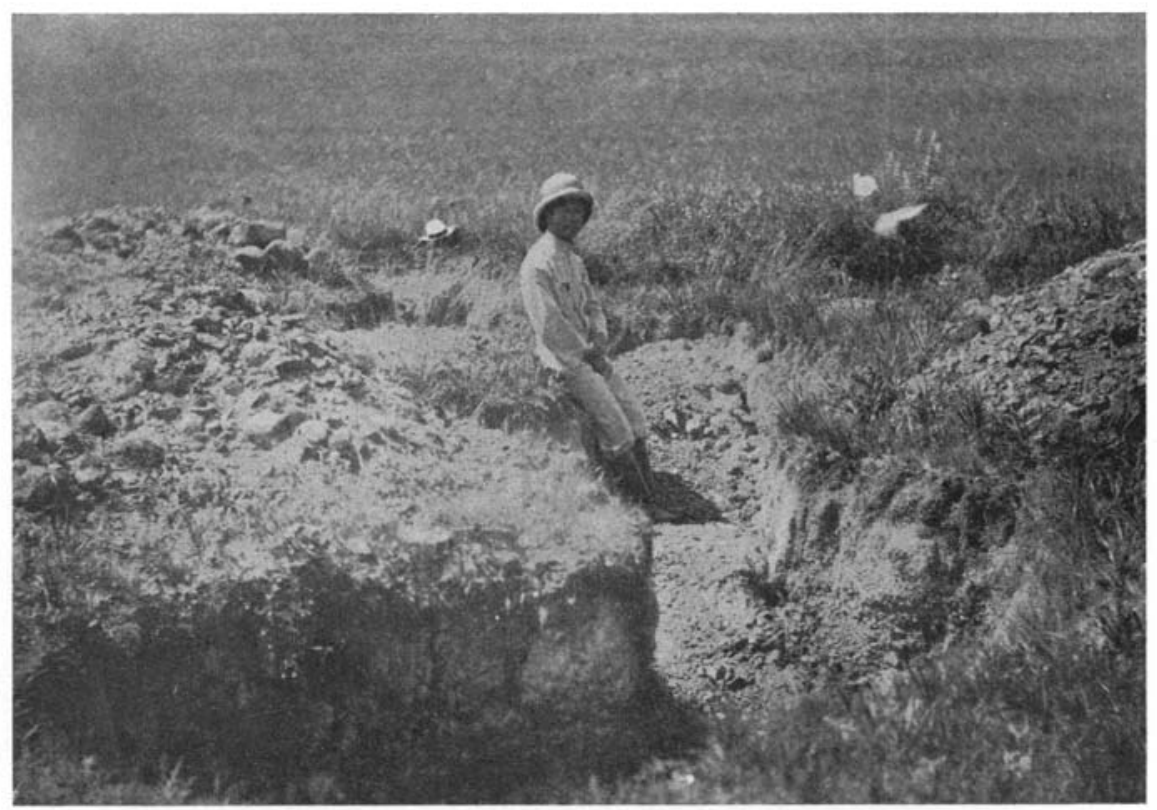

Fig. 18. Tarbagan burrow opened in March, 1911 (winter), partially filled up. 


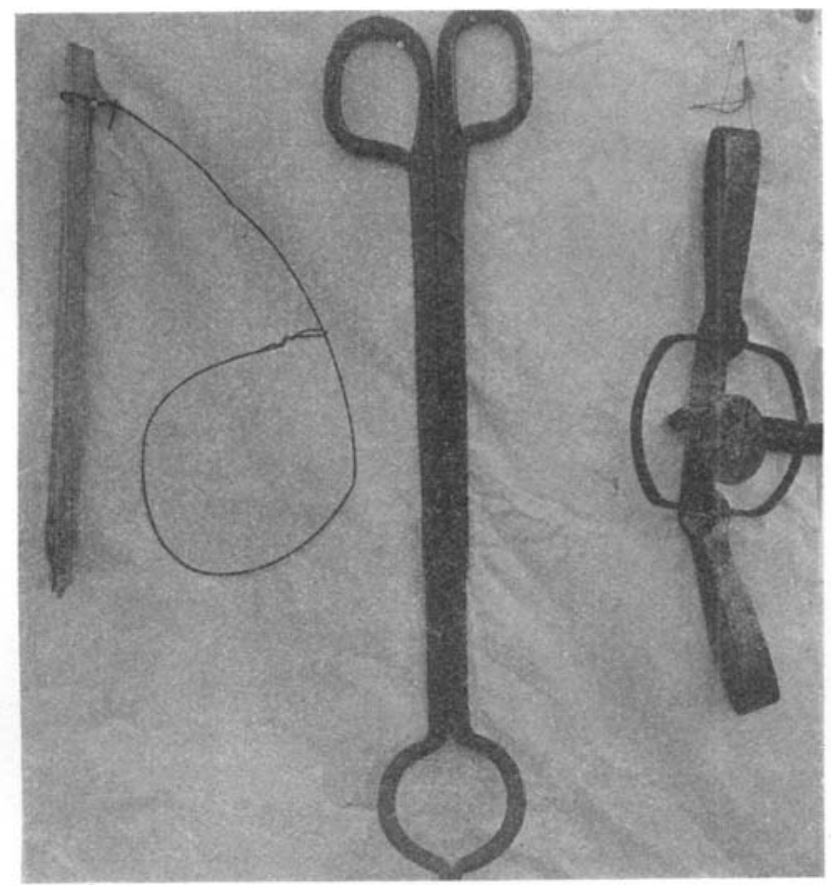

Fig. 19. On the left is a single snare with wooden peg. On the right is a strong trap (rarely used). In the middle, the special forceps.

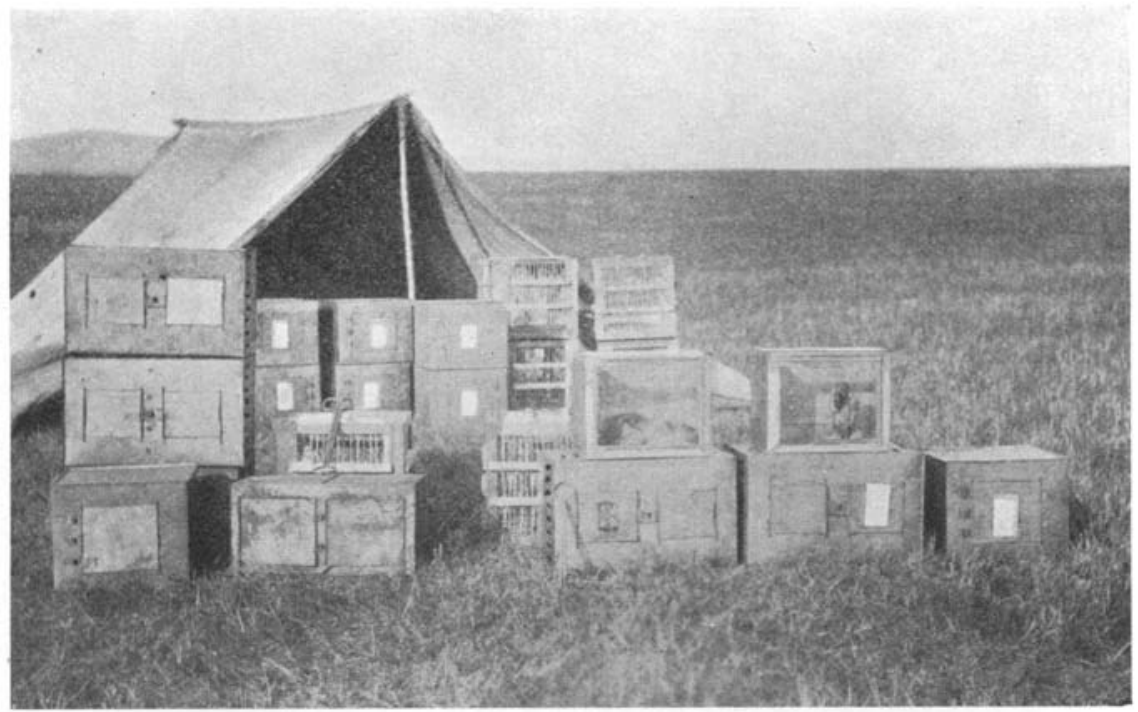

Fig. 20. Tarbagan cages. Manchouli. Aug. 14th-Sept. 30th, 1911. Note various types. 
JOURNAL OF HYGIENE, VOL. XIII. NO. 3

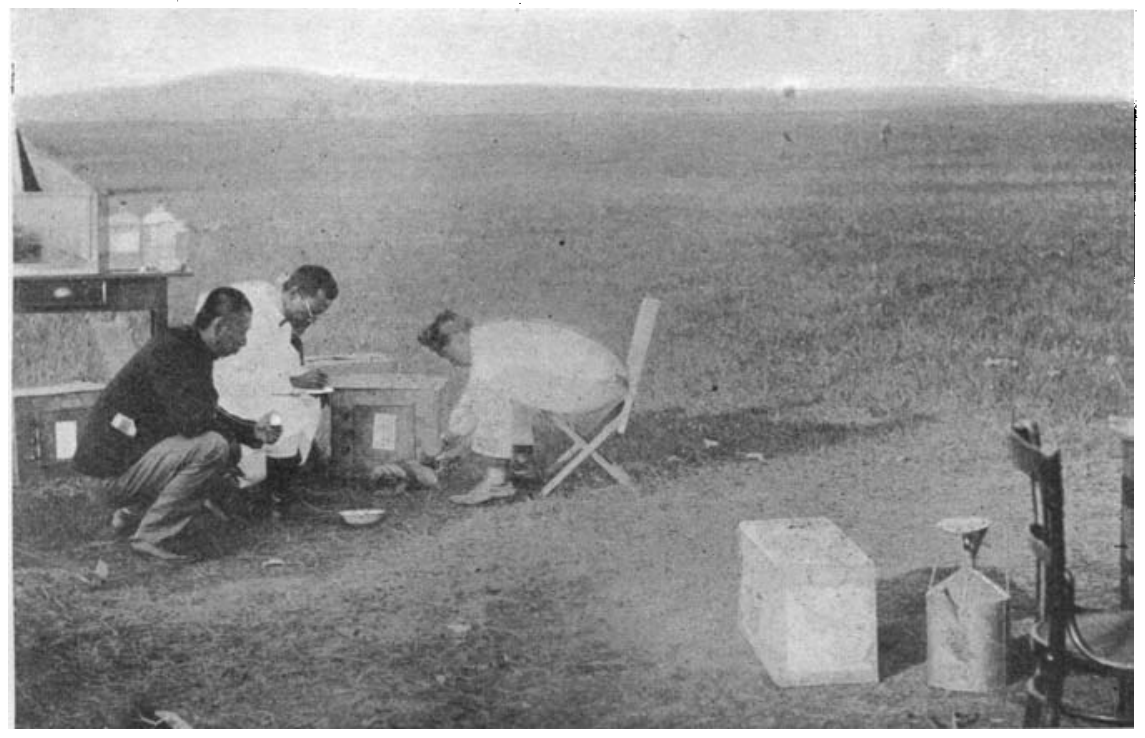

Fig. 21. Taking rectal temperature of Tarbagan. Manchouli.

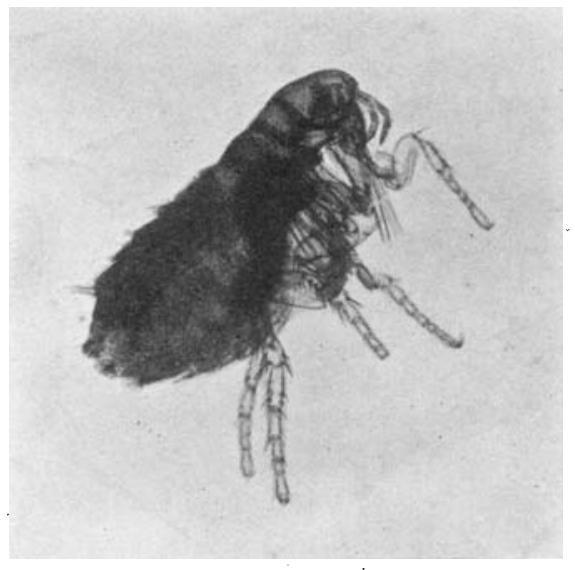

Fig. 22. Ceratophyllus silantievi Wagner. The Tarbagan flea. 